\title{
Exploring the Benefits of Using CryoSat-2's Cross-Track Interferometry to Improve the Resolution of Multisatellite Mesoscale Fields
}

\author{
G. Dibarboure ${ }^{a,{ }^{*}}$, P. Y. Le Traon ${ }^{b}$, N. Galin ${ }^{c}$ \\ ${ }^{a}$ CLS, Ramonville St-Agne, France \\ ${ }^{\mathrm{b}}$ IFREMER, Plouzané, France \\ ${ }^{c}$ Centre for Polar Observation and Modelling, Department of Earth Sciences, University College London, London, \\ United Kingdom \\ *: Corresponding author : Gerald Dibarboure, email address : gerald.dibarboure@cls.fr
}

\begin{abstract}
:
Sea surface height (SSH) measurements provided by pulse-limited radar altimeters are onedimensional profiles along the satellite's nadir track, with no information whatsoever in the cross-track direction. The anisotropy of resulting SSH profiles is the most limiting factor of mesoscale SSH maps that merge the 1D profiles.

This paper explores the potential of the cross-track slope derived from the Cryosphere Satellite-2 (CryoSat-2)'s synthetic aperture radar interferometry (SARin) mode to increase the resolution of mesoscale fields in the cross-track direction. Through idealized 1D simulations, this study shows that it is possible to exploit the dual SARin measurement (cross-track slope and SSH profile) in order to constrain mesoscale mapping in the cross-track direction.

An error-free SSH slope allows a single SARin instrument to recover almost as much SSH variance as two coordinated altimeters. Noise-corrupted slopes can also be exploited to improve the mapping, and a breakthrough is observed for SARin errors ranging from 1 to $5 \mu$ rad for $150-\mathrm{km}$-radius features in strong currents, and $0.1-0.5 \mu \mathrm{rad}$ for global mesoscale.

Although only limited experiments might be possible with the error level of current CryoSat-2 data, this paper shows the potential of the SAR interferometry technology to reduce the anisotropy of altimeter measurements if the SARin error is significantly reduced in the future, and in particular in the context of a prospective SARin demonstrator optimized for oceanography.
\end{abstract}

Keywords: Altimetry, Remote sensing, Sampling, Satellite observations, Interpolation schemes, Inverse methods

\section{Introduction and context}

In contrast with wide-swath imagers (e.g., sea surface temperature or ocean color), the data record of radar altimeters is exceedingly anisotropic. Sea surface height (SSH) measurements from pulselimited radar altimeters are one-dimensional profiles along the satellite's nadir 
track, with no SSH information whatsoever in the cross-track direction. Figure 1 shows that, for a single altimeter flying on the TOPEX/Jason orbit, the along-track (white segment) resolution can be as small as $7 \mathrm{~km}$ (level 2 product, $1 \mathrm{~Hz}$ rate), whereas in the cross-track resolution (black segment) it can be as large as $300 \mathrm{~km}$.

To reconstruct 2D gridded fields of SSH or sea level anomalies (SLA), it is therefore necessary to interpolate 1D profiles (e.g. AVISO 2010; Dibarboure et al, 2011a, Leben et al 2002, 2011). Optimal interpolation (OI) exploits an a priori statistical knowledge of the SLA field characteristics (e.g. Jacobs et al 2001; Le Traon et al, 2003) and measurement error (e.g. Philipps et al, 2012) as an additional constraint to merge 1D profiles from multiple sensors in an optimal way (e.g. Ducet, et al 2000).

The anisotropy of SSH profiles is by far the most limiting factor of gridded SSH mesoscale fields (Le Traon \& Dibarboure, 2002, 2004; Pascual et al 2006), and especially in near real time where measurements "from the map's future" are not yet available (Pascual et al, 2008). There are two practical consequences to this limitation.

Firstly, even if the spatial and temporal scales used to constrain the OI are derived from SSH measurement of 2 to 4 satellite constellations, the mapping is limited in the cross-track direction. Because 1D profiles from multiple sensors are blended into one map, 2D mesoscale mapping uses a compromise between actual mesoscale correlations and the sampling limitations from such constellations (Ducet, et al, 2000).

The resolution of mesoscale fields is dominated by the number of altimeters in operation. Chelton \& Schlax (2003), Le Traon \& Dibarboure (2002), and Chelton et al (2011) have shown that mesoscale maps have a limited global resolution capability. Higher resolution can still be achieved, but only locally, at certain times, when enough 1D profiles are available (Dussurget et al, 2011). 
In this context, a new technology used on CryoSat-2 has the unprecedented potential to add actual measurements to constrain mesoscale mapping in the cross-track direction. Indeed, in addition to a classical pulse-limited radar altimeter measurement (also known as low resolution mode or LRM), CryoSat-2's altimeter SIRAL features a synthetic aperture radar interferometry (SARin) mode able to measure the SSH slope in the cross-track direction (Francis et al, 2007) as illustrated by Figure 2. In this paper, the cross-track slope (CTS) is given in micro-radians: a $1 \mu \mathrm{rad}$ slope is approximately equal to a $\mathrm{SSH}$ gradient of $1 \mathrm{~cm}$ for $10 \mathrm{~km}$, or a geostrophic current of $10 \mathrm{~cm} / \mathrm{s}$ at mid-latitudes.

In this paper we use idealized OI simulations to explore the potential of the CTS derived from CryoSat-2's SARin mode to increase the resolution of mesoscale fields in the cross-track direction (methodology introduced in section 3). Our approach is to look at SARin technology in optimal conditions in section 4 and then to discuss what can be done in practice with current and future datasets in section 5.

\section{Methodology}

\subsection{Overview}

Le Traon and Dibarboure (2002, 2004), Chelton et al (2003) and Dibarboure et al (2011a) have shown that 2D SSH mapping is affected by many parameters (e.g. geometry, phasing or coordination of the constellation's orbits, high frequency ocean dynamics). To measure the potential of using a SARin slope to constrain mesoscale mapping we therefore use a simpler idealized 1D configuration.

We specifically focus on the cross-track direction (black segment from Figure 1) where the resolution is limited by the number of satellites in the constellation. In other words, this is a configuration where SARin slopes are ideal to complement lacking SSH measurements. 
While performed for a given cross-track resolution (i.e. latitude), general conclusions can be derived from our analysis because correlation scales where shown to decrease with latitude as well (e.g. Jacobs et al 2001; Le Traon et al, 2003).

We measure the performance of mesoscale mapping using the following protocol:

- we simulate a mesoscale SSH "reality" profile, and we consider that the reality profile is in a frozen state, i.e. stationary over the 10-day period of a T/P or Jason repeat cycle (this strong assumption is discussed in section 5.3)

- the reality SSH field is sampled on measurement points to create error-free observations,

- errors are optionally added to the observations,

- observations are injected into a 1D optimal interpolator to create a "reconstructed" mesoscale field at the original resolution.

In this process, the statistical variance and correlation scales of the reality field are known analytically. Consequently the reconstruction is perfect if performed from enough error-free observations. In other words, differences between the reality and the reconstructed fields are the result of the omission or sampling error (not enough data to observe the signal) and commission or measurement error.

Note that, there is an additional error source in the mapping of real data: the imperfect modeling of signal and error covariances. This point is discussed in section 5.3.

\subsection{Methodology}

In this paper, we generate our reality $\mathrm{H}_{\text {real }}$ as a spatially correlated random Gaussian process (Equation 1). The default decorrelation scale is $150 \mathrm{~km}$, i.e. consistent with findings from Le Traon et al (2003). In our first simulations (section 4.1), the oceanic variability used is $20 \mathrm{~cm}$ 
111 RMS, i.e. we focus on zones of intense mesoscale activity (e.g. western boundary currents).

112 Then we expand to different signal to error ratios in section 4.2. In section 5.3, we discuss the

113 validity of the Gaussian methodology.

$$
\operatorname{Corr}(H, H)=\exp \left(-x^{2} / d^{2}\right)
$$

Equation 1

114 Our observation field $\mathrm{H}_{\mathrm{obs}}$ is then constructed (Equation 2) by interpolating $\mathrm{H}_{\text {real }}$ at the desired

115 resolution $(30 \mathrm{~km}$ for an along-track simulation, $300 \mathrm{~km}$ for a cross-track simulation on a

116 Jason-like orbit, and $100 \mathrm{~km}$ for a cross-track simulation on the CryoSat-2 orbit) and adding a

117 white noise of 0.5 to $2 \mathrm{~cm}$ to the interpolated SSH values. This is arguably a pessimistic error

118 level at 100+ km if compared with results from Dorandeu et al 2004, or Ablain et al 2011 : the

119 noise they observe at a $7 \mathrm{~km}$ resolution would be reduced by along-track filtering of the SSH

120 (factor of 2 for $30 \mathrm{~km}$ super-observations).

$$
H_{\text {obs }}(x)=H_{\text {real }}(x)+\varepsilon(x)
$$

Equation 2

121 Simulations shown in this paper do not include any along-track bias or long wavelength

122 correlated errors as our sensitivity studies show no significant difference with noise-limited

123 simulations. Although not shown in this paper, our simulated 1D mapping is degraded by

124 correlated errors like operational mesoscale 2D mapping (e.g. Dibarboure et al, 2011c), but

125 the anisotropy effect presented in section 3.3 and the impact of using SARin presented in

126 section 3.5 are the same.

127 The reconstruction of the estimated mesoscale field $\mathrm{H}_{\mathrm{est}}$ is performed with a $1 \mathrm{D}$ optimal

128 interpolation derived from Bretherton et al (1976). $\mathrm{H}_{\text {est }}$ is obtained from Equation 3 where A

129 is the matrix describing the covariance between $\mathrm{H}_{\mathrm{est}}$ and $\mathrm{H}_{\mathrm{obs}}$ of Equation 2, and $\mathrm{C}$ the matrix

130 describing the covariance between the SSH observations (covariances are derived from

131 Equation 1). The formal reconstruction covariance error matrix $\mathrm{E}$ is obtained from Equation 
1324 , although in practice only its diagonal is used here (1- $\sigma$ gray envelope around reconstructed

133 SSH profiles).

$$
H_{\text {est }}=A \cdot C^{-1} \cdot H_{\text {obs }}
$$

134

$$
E=I-A \cdot C^{-1} \cdot A^{\top}
$$

Equation 4

135 Many figures shown in this paper are limited to $3000 \mathrm{~km}$ segments for the sake of illustration

136 but simulations were performed on very long profiles to ensure that the examples in this paper

137 are representative of the statistical behavior of each configuration.

\subsection{Observation anisotropy}

139 Figure 3 shows one reality segment, sampled in the along-track direction (every $30 \mathrm{~km}$ ) with

$1402 \mathrm{~cm}$ white noise added. The reconstructed field after optimal interpolation is almost identical

141 to the reality field. The reconstruction error is $1.2 \mathrm{~cm}$ RMS i.e. $0.4 \%$ of the reality signal

142 variance (18 cm RMS). Similarly, the along-track slope (bottom panel) is almost perfectly

143 observed in the along-track direction.

144 Figure 4 shows the same reality segment, but positioned as a transect in the cross-track

145 direction (black segment from Figure 1). In other words, each measurement (black dot) is the

146 crossover between the transect and a different satellite track. In this figure, the SSH reality is

147 sampled by a LRM altimeter every $300 \mathrm{~km}$, i.e. the worst case configuration of a TP/Jason

148 orbit. Because the Nyquist criterion is not met with a single satellite, many features are

149 missed entirely in the reconstruction (e.g. at $\mathrm{km} \# 1000$ or $\# 1800$ or $\# 2200$ ). The error

150 reconstruction RMS is $46 \%$ of the signal variance. This figure illustrates the inability of a

151 single satellite to observe large mesoscale, let alone features with radii smaller than $150 \mathrm{~km}$.

152 Adding a second LRM altimeter (perfectly coordinated with the first one, i.e. like in the 153 TOPEX/Jason tandem) significantly improves the resolution of the mesoscale field as shown 
154 by Figure 5. Although the Nyquist criterion is barely met, the reconstruction error is

155 significantly reduced with an error of $8 \%$ of the signal variance. The error is consistent and

156 slightly larger than the $5 \%$ obtained by Le Traon et Dibarboure (2002) because this segment

157 represents the widest gap between roughly parallel tracks. These scenarios give the 1-LRM

158 and 2-LRM reference configurations to which SARin experiments can be compared to infer

159 the cross-track slope contribution in an ideal case.

160 The formal mapping error from Equation 4 is visible in each simulation as a grey envelope of

161 vertical bars. This theoretical error is -for these idealized simulations- a very accurate

162 statistical estimate of the error which could be made during the reconstruction process: the

163 differences between the real (plain) and the reconstructed (dashed) SSH are consistent with

164 the 1- $\sigma$ boundaries defined with the grey envelope from Figure 3 and Figure 4.

165 The formal error represents the sum of the measurement error and the sampling error: it is as

166 small as $2 \mathrm{~cm}$ near observation points (measurement noise) and as large as tens of centimeters

167 at the center of the $300 \mathrm{~km}$ window between satellite tracks (sampling error). The anisotropy

168 of the altimetry system is illustrated by the difference between the along-track and the cross-

169 track formal errors. In the along-track direction (Figure 3) the error is always very small and

170 dictated by the measurement error level whereas in the cross-track direction (Figure 4) the

171 sampling error largely dominates between satellite tracks.

\subsection{CryoSat-2's cross-track measurement}

173 CryoSat-2 is ESA's ice mission (Francis, 2007). Equipped with an innovative radar altimeter

174 (SIRAL - Synthetic Aperture Interferometric Radar Altimeter), and high-precision orbit 175 determination (POD), CryoSat-2's primary objective is to serve Cryospheric science

176 (Wingham et al, 2006). Cryosat's altimeter is operated almost continuously over ocean,

177 mainly in LRM (i.e. conventional altimetry) or in the delay doppler / synthetic aperture radar 
178 (SAR) mode which provides higher along-track resolution and lower noise level (Raney, 1998).

180 Furthermore, SIRAL also features a third mode: the SAR-interferometry (SARin) mode, 181 which uses CryoSat-2's two antennas (Francis, 2007). The combination of SAR and 182 interferometry makes it possible to determine the cross-track slope of the surface from which 183 the echoes are arriving. This is achieved by comparing the phase of one receive channel with 184 respect to the other as first suggested by Jensen, 1999.

185 With the SARin mode, CryoSat-2 can provide one estimate of the local CTS every 0.05 186 seconds, in addition to the classical topography measurement (Figure 2). Moreover, the along187 track resolution and the precision of the SSH is the same as for a LRM sensor (e.g. Jason-2). 188 The resolution is $300 \mathrm{~m}$ in the along-track direction (synthetic footprint), and the slope is 189 estimated from a cross-track footprint of the order of $7 \mathrm{~km}$.

190 This unprecedented measurement was initially designed to be used over the margins of the

191 Greenland and Antarctic ice sheets, where the surface slopes are steep. To that extent, 192 SIRAL's SARin mode was designed to have a cross-track slope accuracy of $200 \mu \mathrm{rad}$ 193 (Wingham et al 2006), but Galin et al (2012) reported a noise level of $20 \mu \mathrm{rad}$ at a $7 \mathrm{~km}$ 194 resolution and a bias of $8 \mu \mathrm{rad}$ for $1000 \mathrm{~km}$ segments, using both detailed modeling of the 195 finite radar resolution in range and angle, and the thermally driven behavior of the 196 interferometer bench.

197 This should be compared to the typical mesoscale slope distribution in zones of intense 198 mesoscale activity which ranges from 1 to $5 \mu \mathrm{rad}$ at $150 \mathrm{~km}$ with values higher than $10 \mu \mathrm{rad}$ 199 on the edges of the largest eddies (observed on multi-satellite SSH maps from AVISO, 2010). 200 Assuming that the long wavelength errors described by Galin et al (2012) are minimized with 201 empirical cross-calibration mechanisms (discussed in section 5.2.1), and that the noise level is 
reduced by along-track filtering (discussed in section 5.2.2), it would become possible to use

203 the SARin slope as a constraint for mesoscale mapping in the cross-track direction where

204 LRM altimeters are blind.

205 Because the error level reported on CryoSat-2 is high with respect to the oceanic signal, our 206 rationale is the following: we first look at the benefits of using error-free SARin CTS (section 207 4.1), then we perform sensitivity studies with respect to the ocean variability and 208 measurement errors (section 4.2). From this background, we discuss the practical case of 209 CryoSat-2 in section 5.

\subsection{Improving the reconstruction with the cross-track slope}

211 Figure 2 gives a qualitative illustration of how mesoscale mapping can exploit the SARin 212 cross-track slope. Subplot (a) shows a $500 \mathrm{~km}$ along-track LRM profile with SSH only 213 (simulated, error-free), whereas subplot (b) shows the information given by a SARin profile 214 with SSH and cross-track slope. Both plots correspond to the reality from subplots (c) and (d).

215 From the $\mathrm{SSH}+\mathrm{CTS}$ sample (subplot b), one can assume that the maximum value at $-100 \mathrm{~km}$ 216 is located on the right-hand side of the nadir track, that the minimum value at $+150 \mathrm{~km}$ is 217 probably near the nadir track, and that the maximum value at $+400 \mathrm{~km}$ is located on the left218 hand side of the nadir track. Adding a statistical description of mesoscale variability and 219 slopes, it is possible to enhance the mapping in the cross-track resolution up to a distance 220 equal to the spatial correlation radius.

221 This is achieved using a method derived from Le Traon and Hernandez (1992): we replace the 222 SSH observation vector $\mathrm{H}_{\mathrm{obs}}$ in Equation 3 by a vector composed of all observations (SSH and 223 CTS), and we update matrixes $\mathrm{A}$ and $\mathrm{C}$ from Equation 3 and Equation 4 accordingly (see 224 Appendix). 


\section{Results}

\section{1 $\quad$ Error-free simulations}

227 In this section we infer what would be the optimal mesoscale improvement using SARin on a $228300-\mathrm{km}$ cross-track resolution (i.e. a Jason-like orbit). It is optimal for SARin in the sense that 229 Le Traon and Dibarboure $(2002,2004)$ have shown that the main weakness of this orbit is the 230 cross-track resolution, and it is the reason why TOPEX/Jason and Jason-1/Jason-2 were put in 231 a spatially interleaved configuration. Thus we use this "reference orbit" and "reference 232 tandem" to SARin-based simulations. We discuss the difference between this Jason-like configuration the (suboptimal) Cryosat orbit in section 5.1.

Adding the SARin slope constraint (error free) significantly improves the OI reconstruction as 235 shown by Figure 6. This plot should be compared to Figure 4 where one LRM altimeter was 236 barely able to recover $50 \%$ of the signal variance in the cross-track direction (Nyquist 237 sampling not achieved). Thanks to local constraints on the SSH derivative, it is possible to 238 recover features that were previously missed entirely (e.g. at km \#1800 and \#2200).

239 Quantitatively, on this example, the reconstruction error is only $6.96 \mathrm{~cm} \mathrm{RMS}$, i.e. $15 \%$ of the 240 signal variance (vs. $50 \%$ for the LRM scenario on Figure 4). In other words, about $35 \%$ of the 241 signal variance was recovered with the error-free slope. The 15\% residual error should also be 242 compared to the $8 \%$ of the configuration with two LRM altimeters (Figure 5): in this idealized 243 simulation, a single SARin altimeter performs almost like two LRM altimeters.

244 Similarly, Figure 7 shows that a perfectly coordinated constellation of 2 SARin altimeters 245 flying on a Jason-like orbit (150 km cross-track resolution) is able to properly reconstruct the 246 SSH and slope reality fields even though the Nyquist criterion is barely met with SSH alone. 247 Because slopes and covariance models add the constraint needed, the reconstruction error is 
only $1.83 \mathrm{~cm}$ RMS (i.e. $1 \%$ of the signal variance) and largely due to the error outlier of the

249 first measurement and the $2 \mathrm{~cm} \mathrm{SSH}$ measurement noise.

\subsection{Sensitivity to signal to noise ratio}

251 We performed a series of sensitivity tests on the slope error for 1 and 2 SAR-in altimeter 252 constellations using very long simulations (2000 times the correlation radius). Figure 8 shows 253 the RMS of the error reconstruction as a function of the standard deviation (STD) of the 254 simulated SARin slope error (plain line). The 1-LRM and 2-LRM references are also given by 255 the black dotted and dashed lines. Note that the observed error is consistent with the formal 256 error given by Equation 4.

257 As expected, the reconstruction error decreases as the CTS error does, and the sigmoid shape 258 on the logarithmic abscissa scale indicates that the largest gains are obtained between 1 and 5 $259 \mu \mathrm{rad}$, i.e. near the peak of the cross-track slope probability density function.

260 The upper asymptotic value for slope errors higher than $20 \mu \mathrm{rad}$ is $49 \%$, i.e. the mapping error 261 observed for 1 LRM sensor (dotted line). In other words, if the SARin error is large, it does 262 not improve the reconstruction with the OI. Yet as expected from a theoretical point of view, 263 this figure shows that even if the error STD of the CTS is 25 times larger than the SSH slope 264 STD (i.e. factor of 600 in the covariance matrix), the OI never underperforms w.r.t to the 1265 LRM scenario because untrustworthy observations are automatically downweighted by 266 covariance matrix C.

267 If the OI covariance matrixes are properly set up, adding very noisy slope estimates (e.g. 10 to $26820 \mu \mathrm{rad}$ unmitigated error from Galin et al, 2012) can still improve the cross-track mapping, 269 albeit in a very limited way. 
The lower asymptotic value is $13 \%$ of the signal variance, i.e. only slightly larger than the $9 \%$ error observed with 2 LRM sensors (dashed line): using an error-free SARin instrument in an ideal configuration (1D, cross-track, $150 \mathrm{~km}$ radius for a $300 \mathrm{~km}$ sampling resolution) does not allow to fully reconstruct the signal, but a single SARin instrument yields results almost as good as two LRM sensors as per the example from Figure 5 and Figure 6. The residuals arise from sampling errors: although additional error-free parameters are used, there are still not enough measurements points to correctly resolve all mesoscale structures.

Results are similar for $2 \times$ SARin simulations in Figure 9, even though the gain is more limited owing to the fact that 2 coordinated LRM altimeters already have a good sampling capability for $150 \mathrm{~km}$ radius features (Le Traon et Dibarboure, 2004). In this figure, the lower asymptotic value is $1.2 \%$, i.e. very close to the $1 \%$ obtained with 4 coordinated LRM sensors: sampling errors would become marginal in a coordinated $2 \mathrm{x}$ SARin configuration.

Because the variability of the cross-track slope is proportional to the variability of the SSH, we performed sensitivity studies to the latter (using constant correlation scales and SSH noise levels) to see how results from section 4.1 could be extrapolated out of intense mesoscale activity zones.

Figure 10 confirms that the reconstruction error is still sigmoid-shaped, and shifted along the abscissa axis as a function of the SSH variability. The breakthrough in mapping improvement is always achieved for slope error STD ranging from $0.5^{*} \sigma_{\text {slope }}$ to $2^{*} \sigma_{\text {slope. }}$

To be used globally in mesoscale mapping, SARin slopes would require an error level of the order of 0.1 to $0.5 \mu \mathrm{rad}$ for mesoscale wavelengths. This is largely beyond what can be achieved with current data from Cryosat-2 (discussed in section 5.2). 


\section{Discussion: from theory to practice}

\subsection{Sensitivity to the satellite track geometry}

294 The sampling pattern of the CryoSat-2 orbit (current SARin mission) and the Jason orbit 295 (simulations from section 4) are very different. The latter has a 10-day repeat cycle (300 km 296 cross-track resolution from Figure 1). In contrast, CryoSat-2 has a one-year repeat cycle with 297 3-day and 30-day sub-cycles, i.e. globally homogeneous sampling patterns with 1000 and 100 298 km cross-track resolutions respectively (Francis et al, 2007). CryoSat-2's orbit has no sub299 cycle in the 10 to 20 day range associated with mesoscale temporal decorrelation (Jacobs et 300 al, 2001).

301

302

303

304

305

As a result, for any 10 to 20 day period, CryoSat-2's measurements are aggregated in bandshaped patterns (100 km wide per 3-day sub-cycle) which are interleaved with band-shaped "blind spots" with no recent SSH observation (Figure 11). The impact on mesoscale observation in LRM mode is discussed by Dibarboure et al (2011c). As far as SARin slopes are concerned, there are two consequences of CryoSat-2's sampling pattern.

\subsubsection{Track aggregation and data gaps}

Firstly the SARin slopes located on the outer edges of the band-shaped aggregation of satellite tracks provide a unique capability to reduce the extent of the band-shaped blind spots by up to $2 * 150 \mathrm{~km}$ (one slope constraint on each side of the diamond not covered by CryoSat-2 tracks in Figure 11). This is useful to balance CryoSat-2's main sampling weakness when it comes to mesoscale observation.

Figure 12 illustrates this point: it shows the OI reconstruction for a $1500 \mathrm{~km}$ cross-track segment where CryoSat-2 measurements are aggregated in $100 \mathrm{~km}$ resolution bands where mesoscale features (150 km radius) are resolved, and interleaved with a $500 \mathrm{~km}$ wide blind 
spot where no CryoSat- 2 track is available in the 15 day window corresponding the frozen

316 field approximation.

317 The SARin-based reconstruction (subplot a) is slightly better because the outer edges are

318 constrained by error-free slope estimates whereas the LRM-based reconstruction (subplot b)

319 is not able to observe even a fraction of the large eddy at km \#700 and the total reconstruction

320 error is much higher (12.1 cm RMS vs. $6.7 \mathrm{~cm}$ RMS for SARin). Note that the overall

321 improvement is limited to the outer edges of the large data gap (one decorrelation radius on

322 each side) because the OI cannot "guess" the existence mesoscale structures if they are not

323 remotely observed.

\subsubsection{Orbit sampling differences}

The second consequence of CryoSat-2's sampling pattern is the cross-track resolution within the track aggregations. CryoSat-2's sampling "bands" have a cross-track resolution of 100 $\mathrm{km}$, i.e. more favourable to the observation of $150 \mathrm{~km}$ radius mesoscale features, albeit in limited areas. In this context, SARin data from Cryosat might be used to recover smaller mesoscale features (only within the satellite track aggregation).

Table 1 shows the mapping improvement (i.e. the reduction of cross-track reconstruction 331 error) when the "reality" and OI correlation radiuses range from 50 to $150 \mathrm{~km}$ and for the 332 Jason and CryoSat-2 orbits. All simulations were performed with a slope measurement noise 333 of $1 \mu \mathrm{rad}$. On the Jason orbit, the cross-track mapping is improved mainly for large mesoscale $334(18 \%)$ but not for short mesoscale $(5 \%)$ because the SARin slope cannot balance the limited 335 resolution of the Jason orbit. The opposite is observed for CryoSat-2 (in the aggregation 336 bands) owing to its cross-track $100 \mathrm{~km}$ cross-track resolution: the improvement is limited for $337100 \mathrm{~km}$ or more and the highest improvement is observed for a $50 \mathrm{~km}$ radius. 
338 In other words, with the CryoSat orbit, the SARin slope is an asset to improve the cross-track

339 observation of smaller mesoscale features (in the band-shaped aggregation of satellite tracks),

340 something that would not be possible on a Jason orbit.

341 Yet higher wavenumber $(\mathrm{K})$ mesoscale eddies also have a smaller amplitude (the SSH power 342 spectrum decreases as a function of $\mathrm{K}^{-11 / 3}$ in the SQG theory, as per Le Traon et al., 2008).

343 Thus changing the correlation radius also induces a reduction of the SSH STD and a reduction

344 of the CTS STD from $2 \mu \mathrm{rad}$ to $1.5 \mu \mathrm{rad}$ (Table 1). In other words, higher precision SARin 345 slopes would be needed in CryoSat-2's sampling bands because the smaller signal of interest 346 also has weaker slopes.

347 To that extent, and considering the error level discussed in section 5.2, the CryoSat-2 orbit is 348 less attractive than a Jason-like resolution would be, because the gain with SARin is 349 geographically limited and because the orbit is more demanding in terms of CTS error budget.

\section{$5.2 \underline{\text { Slope error }}$}

351 The simulations from section 4.2 showed that the enhancement of cross-track mesoscale 352 mapping was possible in favorable signal to ratio conditions. The expected benefit from actual 353 Cryosat-2 data raises the question of the error level of current datasets. Yet the error spectrum 354 of SARin data in a mesoscale context is not known. Indeed, SARin acquisition zones on 355 ocean are small and/or limited in time. So it is not possible to get datasets that are large 356 enough to observe correlated errors in space or in time. The study from Galin et al (2012) is 357 the first to provide a CTS error estimate as a bias and noise error on ocean through a 358 comparison with a geoid model. 
360 Galin et al (2012) report biases of the order of $8 \mu \mathrm{rad}$ on their $1000 \mathrm{~km}$ segments. It is not so 361 much a true bias, as a long wavelength correlated error (e.g. orbital revolution) since they also 362 observe a correlation with thermal conditions on the orbit (i.e. linear on $1000 \mathrm{~km}$ segments). 363 Yet, in this paper, we are ignoring biases and long wavelength errors because we assume that 364 they can be accounted for by multi-satellite cross-calibration.

365 Indeed, at the intersection of satellite tracks (e.g. CryoSat-2 x CryoSat-2 or CryoSat- $2 \times$ 366 Jason-2) crossovers points provide a double measurement where the actual SSH anomaly 367 signal is partially cancelled if the temporal distance between both measurements is short 368 enough. It is thus possible to use this observation to detect and to mitigate spatially and 369 temporally correlated signals.

370 Tai et al (1988) have used this approach to empirically reduce orbit errors on the SSH and 371 Dibarboure et al (2011b) have demonstrated the feasibility of reducing the cross-track slope 372 error for the wide-swath altimetry mission SWOT. So, in theory, the same method could be 373 used to reduce CryoSat-2's SARin slope biases. The method would exploit crossover 374 observations using a combination of the along-track and cross-track slope for SARin / SARin 375 crossovers, and a projection of the along-track slope into the opposite along-track plane for 376 SARin / LRM crossovers.

377 Alternatively, long wavelength errors (500 km or more) can be accounted for in the mapping 378 process itself, with an approach derived from Ducet et al (2000). These techniques are used 379 operationally to remove $\mathrm{SSH}$ biases and $1000 \mathrm{~km}$ errors before mesoscale mapping 380 (Dibarboure et al, 2011a), including for datasets with limited coverage (e.g. ERS-2 after the 381 loss of its on board recorders). The same method could be used in the geographically-limited 382 SARin acquisition zones to cross-calibrate long-wavelength errors in the cross-track slope. 


\subsubsection{Noise and short scale errors}

384 In the recovery of the cross-track slope, Galin et al (2012) also observe on average $20 \mu \mathrm{rad}$ of 385 speckle-related noise at $1 \mathrm{~Hz}$ or $7 \mathrm{~km}$ resolution. The slope is computed from a distance 386 ranging from $1 \mathrm{~km}$ to $8 \mathrm{~km}$ depending on the retrieval algorithm (phase-difference at the first 387 point of arrival VS. model fit) and significant wave height (SWH) conditions.

The spatial correlation of mesoscale slope makes along-track filtering possible (including with non linear filters to remove spurious slopes) if the error is speckle-related (i.e. no along-

390 track correlation of the CTS error). If we assume that a simple running average is used to get 391 one super-observation for a $150 \mathrm{~km}$ radius (admittedly a crude filtering), the resulting 392 mesoscale slope precision would be less than $4 \mu \mathrm{rad}$ with current slope retrieval algorithms.

393 Moreover, Galin et al investigate the origin of residual SARin slope outliers such as the 394 influence of wind and so-called sigma0 blooms. Yet sigma0 blooms can be detected and 395 edited out in pulse-limited LRM altimetry (Thibaut et al, 2010). We can therefore assume that 396 the largest SARin slope outliers can be detected as well, thus decreasing the overall slope 397 error RMS of a non-Gaussian slope error distribution.

398 With Cryosat-2 we can probably observe only large eddies (2- $\sigma)$ in zones of intense 399 mesoscale variability. Elsewhere, SARin slopes from Cryosat-2 can probably barely improve 400 cross-track mesoscale mapping because the instrument was not designed for this application 401 (insufficient signal to error ratio).

\subsubsection{MSS and geoid errors}

403 In this section, we discuss MSS model errors and their influence on SARin slope anomalies in 404 the context of mesoscale mapping. Indeed, mesoscale mapping is based on sea level 405 anomalies (SLA), not sea surface heights (Dibarboure et al, 2012) and the SLA is created as 
406 the difference of the measured $\mathrm{SSH}$ and a temporal reference or $<\mathrm{SSH}>$. The orbit used by

407 CryoSat-2 is geodetic (one-year repeat cycle, described in Francis et al, 2007) so gridded 408 MSS or geoid models are used as a $<\mathrm{SSH}>$ reference. The same stands for CTS anomalies 409 which are the difference of the CTS measurement and the cross-track gradient of the MSS 410 model. Consequently any error in the models generates a CTS anomaly error (i.e. an 411 additional CTS error in Figure 10).

412 Pavlis et al (2008) show that in favourable conditions along the well-known TOPEX/Poseidon 413 tracks, they observe an error of $2 \mu \mathrm{rad}$ at $1 \mathrm{~Hz}$ for EGM08. In a different context, Sandwell 414 and Smith (2009) have shown through comparisons with shipboard gravity that the accuracy 415 of altimetry-derived gridded gradients was of the order of a few $\mu$ rad in zones of rugged 416 seafloor topography. More recently, Schaeffer et al (2012) have shown that the gradient error 417 of their MSS model (CNES/CLS2011) ranged from $1 \mu \mathrm{rad}$ along charted tracks of repetitive 418 altimetry mission to $5 \mu \mathrm{rad}$ in areas covered only by geodetic altimetry missions. Moreover, 419 Andersen \& Rio (2011) and Dibarboure et al (2012) highlighted differences between 420 independent MSS models that range from 1 to $3 \mathrm{~cm}$ with wavelengths ranging from 3 to 421 hundreds of kilometers (a few $\mu$ rad after along-track smoothing).

422 The MSS/geoid error is therefore quite significant in the error budget of a SARin CTS 423 anomaly, since it would add up to noise estimates from section 5.2.2. That error alone would 424 make error-free CTS measurements difficult to use except in zones of strong mesoscale 425 activity.

\subsubsection{Expected and possible improvements}

427 Comparing the figures of merit from section 5.2 to the sensitivity studies from section 4.2 428 shows that the precision needed to improve cross-track mesoscale mapping in strong currents 429 is at the limit of CryoSat-2's current observation capability. 
430 However, one might expect some improvements in the future. The primary error sources were 431 shown to be speckle-related measurement noise and the MSS reference models used to 432 generate the slope anomaly.

433 Concerning the former, it might be technically possible to update onboard software to get 434 SAR data from both receive chains on ocean, and to change acquisition rates in SARin mode, 435 essentially yielding 4 times as many independent looks, and reducing the noise level. 436 Moreover, the SAR and SARin retrieval algorithms are relatively young, especially in an 437 oceanography context (CryoSat-2 is an ice mission), and Galin et al give some interesting 438 outlook that might result in a better precision: filtering, and weighting of beams...

439 And concerning the latter, our error estimate are derived from 2008-2001 generation MSS 440 models, which are not yet integrating new geodetic data from CryoSat-2, Jason-1 GM 441 (geodetic phase), let alone from new and upcoming missions flying on uncharted tracks (e.g. 442 Sentinel-3A and 3B, HY-2). It is likely that the current and future altimeter datasets will 443 decrease the error level of the future reference models, and especially at short wavelengths.

444 Beyond CryoSat-2, our findings raise the question of a prospective SARin demonstrator 445 optimized for oceanography (with synergies with other applications). In this context, the 446 outlook is even more promising because additional changes could be considered: on the orbit, 447 on the hardware, and reference surface models.

448 CryoSat-2's orbit was shown to be suboptimal for SARin usage in section 5.1 and a dedicated 449 mission could use a different orbit such as the ones analyzed by Dibarboure et al (2012) for 450 the geodetic phase of Jason-1.

451 Moreover, if a new instrument derived from SIRAL were used on a dedicated SARin 452 demonstrator, various upgrades could be considered to increase the number of statistically 453 independent looks and to decrease the speckle-related noise: antenna design and beam width, 
454 baseline length, pulse timing (e.g. continuous or interleaved mode VS SIRAL's burst 455 mode)... However it is possible that the global mesoscale requirement from section 4.2 456 (precision of the order of 0.1 to $0.5 \mu \mathrm{rad}$ ) might remain challenging.

457 Lastly, in the context of global SARin acquisition with a sufficient precision, such a 458 prospective mission would acquire east/west gradients which would help resolve the shortest 459 wavelengths in MSS, geoid or bathymetry models since they are difficult to resolve with the 460 current anisotropy of altimeter data (Sandwell et al,, 2011). In turn, this would further 461 mitigate the errors from the $<\mathrm{SSH}>$ reference discussed in section 5.2.3.

\subsection{Validity and limitations of this work}

463 In this section we discuss some approximations made in this paper, and the validity and 464 limitations of these factors as an outlook for future work: the Gaussian properties of our 465 "reality", the perfect a priori knowledge used in the mapping process, the simple 1D mapping 466 methodology used, and the lack of temporal variability.

- In section 3.2, our reality is a random Gaussian process with a decorrelation function consistent with scales reported by Le Traon et al (2003). In practice, our reality has a flat power spectrum density for long wavelengths and a cut-off for shorter wavelengths. In other words, we do not use the covariance model from operational mesoscale mapping (e.g. Ducet et al, 2010), but our covariance model and the associated variance-preserved power spectra are representative of a diversity of wavelengths, much like along-track filtered altimeter measurements.

- In the OI, we use a priori knowledge of the covariance of the signal $\left(\mathrm{H}_{\text {real }}\right)$ and the covariance of the error $(\epsilon)$ in matrices $\mathrm{A}$ and $\mathrm{C}$ from Equation 3. In this paper, we use the true analytical covariance model used to simulate our dataset (i.e. the covariance 
model of our Gaussian reality), resulting in a non-existent mapping error for error-free measurements. However, in practice, we only have an approximate knowledge of the true ocean decorrelation model (e.g. Jacobs et al, 2001 or Le Traon et al 2003) and of the altimetry error, so the OI process is not perfect. The same stands for the CTS parameter, and the a priori knowledge of the SARin data error. This can be a significant implementation problem so our findings should be revisited with real data. More importantly, this point highlights that one must acquire a better understanding of

- Lastly one should note that the frozen field assumption and the $1 \mathrm{D}$ analysis (crosstrack direction) represent a best case configuration for SARin. In reality, mesoscale signals temporally decorrelate over \pm 15 to 20 days. Thus our results are optimistic because they do not take into account the high frequency dynamics that Le Traon and Dibarboure (2002) showed to be difficult to resolve with constellations with less than 4 altimeter missions. There is also a large panel of complex geometric configurations that vary with latitude. Consequently, because $1 \mathrm{D}$ results are encouraging, the findings of this paper should be extended to much more sophisticated 3D simulations (OI or ocean model assimilation), taking into account orbit sampling dynamics (measurements are not ubiquitous, nor regularly spaced out) and the temporal variability of the ocean (reality is not frozen).

\section{Conclusion}

CryoSat-2's SAR interferometry (SARin) mode has the unprecedented capability to measure the sea surface height slope in the cross-track direction. It is possible to use this parameter to constrain mesoscale mapping, and to improve the resolution in the cross-track direction where the traditional (LRM) radar altimetry is limited by the number of satellites in operations. 
501 Idealized mapping simulations show that a single error-free SARin sensor on a Jason-like

502 orbit has the potential to perform almost like two coordinated LRM instruments. Sensitivity 503 studies show that the breakthrough in mapping improvement is achieved for slope errors

504 between 1 and $5 \mu \mathrm{rad}$ for $150 \mathrm{~km}$ macro-observations, in zones of intense mesoscale activity.

505 A better slope precision of the order of $0.1 \mu \mathrm{rad}$ would be needed for global usage and/or to

506 resolve smaller features (radius $<100 \mathrm{~km}$ ).

507 The precision needed to improve cross-track mesoscale mapping is probably at the limit of 508 current SARin products from CryoSat-2 (and only after multi-satellite cross-calibration and 509 along-track filtering) which might observe only the strongest slopes $(2-\sigma)$ in very energetic 510 areas. The proof of concept is more attractive if we extrapolate to future improvements of 511 SARin processors and ancillary datasets (e.g. MSS) and to a prospective mission improving 512 upon SIRAL hardware and CryoSat-2 processors.

513 While encouraging, these results are optimistic, because all simulations were performed on a

514 frozen SSH field (ocean dynamics and high frequencies are not taken into account), and only 515 in the cross-track direction (i.e. optimal for the SARin slope) and they should be extended to 516 much more complex 3D studies, or with real data from CryoSat-2.

\section{$517 \quad 7$ Acknowledgements}

518 This work was co-funded by the MyOcean Project and CNES. The authors would like to 519 thank Pr. Duncan Wingham from the University College London, and Dr. Robert Cullen from 520 ESA/ESTEC, and Dr Laurent Phalippou from T.A.S for their help. 


\section{Appendix: CTS methodology}

522 To use the cross-track slope in the OI process, we use the following covariance models to

523 describe the relationship between the topography $\mathrm{H}$ and the slope $\mathrm{S}$ :

$$
\begin{gathered}
\operatorname{cov}_{h h}(\tau)=K \cdot e^{-\left(\frac{\tau}{d}\right)^{2}} \\
\operatorname{cov}_{h s}(\tau)=-\frac{2 \tau}{d^{2}} \cdot K \cdot e^{-\left(\frac{\tau}{d}\right)^{2}} \\
\operatorname{cov}_{s S}(\tau)=K \cdot\left(\frac{4 \tau^{2}}{d^{4}}-\frac{2 \tau}{d^{2}}\right) \cdot e^{-\left(\frac{\tau}{d}\right)^{2}}
\end{gathered}
$$

524 To inverse the problem, we replace $\mathrm{A}$ and $\mathrm{C}$ and $\mathrm{H}_{\mathrm{obs}}$ from Equation 3 (and Equation 4), by $525 \mathrm{~A}^{\prime}, \mathrm{C}^{\prime}$ and $\mathrm{H}^{\prime}$ obs, where $\mathrm{H}^{\prime}$ obs is the new observation vector including topography and slope 526 measurements as the sum of the true signal $\mathrm{H}_{\text {real }}$ or $\mathrm{S}_{\text {real }}$ and a random error $\varepsilon_{\mathrm{H}}$ and $\varepsilon_{\mathrm{S}}$ 527 estimated on the across-track position vector $\mathrm{x}(\mathrm{i})$ :

$$
H^{\prime}{ }_{\text {obs }}=\left[\begin{array}{c}
H_{\text {real }}(x(1))+\varepsilon_{H}(x(1)) \\
\vdots \\
H_{\text {real }}(x(N))+\varepsilon_{H}(x(N)) \\
\vdots \\
S_{\text {real }}(x(1))+\varepsilon_{S}(x(1)) \\
\vdots \\
S_{\text {real }}(x(1))+\varepsilon_{S}(x(N))
\end{array}\right]
$$

Equation 8

528 Matrix C' is the new covariance matrix taking into account both topography and slope 529 estimates

$$
C^{\prime}=\left[\begin{array}{ll}
C_{h h} & C_{h s} \\
C_{h s} & C_{s s}
\end{array}\right]
$$


where $C_{h h}, C_{h s}$, and $C_{s s}$ are the three covariance matrixes for each couple of observation type,

531 built as a function of the distance $d_{i, j}=|x(i)-x(j)|$ separating measurements points \#i and \#j.

$$
\begin{aligned}
& C_{h h}=\left[\begin{array}{ccc}
\operatorname{cov}_{h h}\left(d_{1,1}\right) & \ldots & \operatorname{cov}_{h h}\left(d_{1, N}\right) \\
\vdots & \operatorname{cov}_{h h}\left(d_{i, j}\right) & \vdots \\
\operatorname{cov}_{h h}\left(d_{N, 1}\right) & \ldots & \operatorname{cov}_{h h}\left(d_{N, N}\right)
\end{array}\right] \\
& C_{h s}=\left[\begin{array}{ccc}
\operatorname{cov}_{h s}\left(d_{1,1}\right) & \ldots & \operatorname{cov}_{h s}\left(d_{1, N}\right) \\
\vdots & \operatorname{cov}_{h s}\left(d_{i, j}\right) & \vdots \\
\operatorname{cov}_{h s}\left(d_{N, 1}\right) & \ldots & \operatorname{cov}_{h s}\left(d_{N, N}\right)
\end{array}\right] \\
& C_{S S}=\left[\begin{array}{ccc}
\operatorname{cov}_{S S}\left(d_{1,1}\right) & \ldots & \operatorname{cov}_{S S}\left(d_{1, N}\right) \\
\vdots & \operatorname{cov}_{S S}\left(d_{i, j}\right) & \vdots \\
\operatorname{cov}_{S S}\left(d_{N, 1}\right) & \ldots & \operatorname{cov}_{S S}\left(d_{N, N}\right)
\end{array}\right]
\end{aligned}
$$

532 When the inversion is optimal we also account for the uncorrelated error $\varepsilon_{\mathrm{H}}$ and $\varepsilon_{\mathrm{S}}$ in the diagonal of $\mathrm{C}_{\mathrm{hh}}, \mathrm{C}_{\mathrm{hs}}$, and $\mathrm{C}_{\mathrm{ss}}$ (not shown).

Matrix A' describing the covariance between the topography we want to reconstruct $\mathrm{H}_{\mathrm{est}}$ and the new observation vector $\mathrm{H}^{\prime}$ obs is created with the method used for $\mathrm{C}^{\prime}$, but using the distance $d^{\prime}{ }_{i, j}$ between the position $x(i)$ of our observation points and the position $x$ '(i) our unknown grid points.

\section{$9 \underline{\text { References }}$}

- Ablain. M, S.Philipps, N.Picot, E.Bronner (2010): Jason-2 global statistical assessment and cross-calibration with Jason-1. Marine Geodesy, volume 33 supplement 1, doi: 10.1080/01490419.2010.487805

- Andersen.O., Rio.M-H. (2011): On the accuracy of current mean sea surfaces models. Proceedings of the 2011 Ocean Surface Topography Science Team Meeting (San Diego). http://www.aviso.oceanobs.com/en/courses/sci-teams/ostst-2011/index.html

○ AVISO (2010): SSALTO/DUACS User Handbook : (M)SLA and (M)ADT Near-Real Time and Delayed Time Products, CNES document SALP-MU-P-EA-21065-CLS, latest version available on AVISO website: http://www.aviso.oceanobs.com/en/data/tools/aviso- 
- AVISO (2011): Cal/Val and cross-calibration annual reports : http://www.aviso.oceanobs.com/es/calval/systematic-calval/index.html

○ Bretherton, F. P., Davis, R. E., and Fandry, C. B., (1976): A technique for objective analysis and design of oceanographic experiment applied to MODE-73. Deep-Sea Research, 23:559-582

- Chelton, D. B., and M. G. Schlax (2003): The accuracies of smoothed sea surface height fields constructed from tandem altimeter datasets. J. Atmos. Oceanic Technol., 20, 12761302, 2003.

- Chelton, D. B., M. G. Schlax, and R. M Samelson, 2011: Global observations of nonlinear mesoscale eddies. Prog. Oceanogr., 91, 167-216.

○ Cullen.R., D.J. Wingham, P. Viau, C.R. Francis, C. Mavrocordatos (2007): ESA's CryoSat-2 Multimode Level 0 to Level1B science processors - Algorithm design and relaunch verification with ASIRAS. Proceedings of the ENVISAT 2007 Symposium

○ Dussurget.R., Birol.F., Morrow.R., De Mey.P. (2011): Fine Resolution Altimetry Data for a Regional Application in the Bay of Biscay, Marine Geodesy, Vol. 34, Iss. 3-4, 2011

- Dibarboure.G., M-I.Pujol, F.Briol, PY.Le Traon, G.Larnicol, N.Picot, F.Mertz, M.Ablain (2011a): Jason-2 in DUACS: first tandem results and impact on processing and products. , Marine Geodesy, 34:3-4, 214-241. doi: 10.1080/01490419.2011.584826

○ Dibarboure.G., Labroue.L., Ablain.M., Fjørtoft.R., Mallet.A., Lambin.J., Souyris.J.C. (2011b) : Empirical cross-calibration of coherent SWOT errors using external references and the altimetry constellation, Transactions on Geoscience and Remote Sensing (in press, 10.1109/TGRS.2011.2171976)

○ Dibarboure.G., Renaudie.C., Pujol.M-I, Labroue.S., Picot.N. (2011c): A demonstration of the potential of CryoSat-2 to contribute to mesoscale observation. Advances in Space Research (in press). doi : 10.1016/j.asr.2011.07.002

○ Dibarboure.G., P.Schaeffer, P.Escudier, M-I.Pujol, J.F.Legeais, Y.Faugère, R.Morrow, J.K.Willis, J.Lambin, J.P.Berthias, N.Picot (2012): Finding desirable orbit options for the "Extension of Life" phase of Jason-1. Marine Geodesy (In Press).

○ Dorandeu. J., Ablain.M., Faugere.Y., Mertz.F., Soussi.B., Vincent.P (2004): Jason-1 global statistical evaluation and performance assessment: Calibration and cross-calibration results. Marine Geodesy, Vol. 27, Iss. 3-4, 2010, doi : 10.1080/01490410490889094

○ Ducet, N., P.Y. Le Traon and G. Reverdin, (2000): Global high resolution mapping of ocean circulation from the combination of TOPEX/POSEIDON and ERS-1/2. Journal of Geophysical Research (Oceans), 105, C8, 19,477-19,498.

- Francis, C.R., (2007): "Mission and Data Description", CS-RP-ESA-SY-0059, issue 3. ESA document. http://esamultimedia.esa.int/docs/CryoSat-2/Mission_and_Data_Descrip.pdf

○ Galin.N., Wingham.D., Cullen.R., Fornari.M., Smith.W. (2011a): Measurement of the cross-track slope of the marine geoid with SAR-interferometric altimeter. Presented at the 2011 Ocean Surface Topography Science Team meeting (San Diego, Oct 2011) http://depts.washington.edu/uwconf/ostst2011/agenda.html

○ Galin.N., Wingham.D., Cullen.R., Fornari.M., Smith.W., Abdalla.S. (2012): Calibration of the CryoSat-2 Interferometer and Measurement of Cross-track Ocean Slope. Transactions on Geoscience and Remote Sensing (in press), doi: 10.1109/TGRS.2012.2200298

○ Jacobs, G., C.Barron, R.Rhodes (2001): Mesoscale characteristics, Journal of Geophysical Research, VOL. 106, NO. C9, PP. 19,581-19,595, 2001

○ Jensen, J. R. (2009): Angle measurement with a phase monopulse radar altimeter, IEEE Trans. Antennas. Propagation, vol. 47, pp. 715-724, 1999. 
○ Labroue.S., F.Boy, N.Picot, M.Urvoy, M.Ablain (2011b): First Quality Assessment of the CryoSat-2 Altimetric System over Ocean. Submitted to ASR special issue "Oceanography, Cryosphere, and Freshwater Flux to the Ocean".

○ Leben.R., LoDolce.G. (2011): The New CCAR "Eddy" Ocean Data Server. Proceedings of the 2011 Ocean Surface Topography Science Team Meeting (San Diego). http://www.aviso.oceanobs.com/en/courses/sci-teams/ostst-2011/index.html

○ Leben.R., Born.G., Engebreth.B. (2002): Operational Altimeter Data Processing for Mesoscale Monitoring, Marine Geodesy, Vol. 25, Iss. 1-2, 2010

- Le Traon, P. Y., M. C. Rouquet, and C. Boissier (1990), Spatial Scales of Mesoscale Variability in the North Atlantic as Deduced From Geosat Data, J. Geophys. Res., 95(C11), 20,267-20,285, doi:10.1029/JC095iC11p20267.

○ LeTraon, P. Y., and F. Hernandez, (1992): Mapping the oceanic mesoscale circulation: Validation of satellite altimetry using surface drifters. J. Atmos. Oceanic Technol., 9, 687-698.

○ Le Traon, P. Y., and G. Dibarboure, (2002): Velocity Mapping Capabilities of Present and Future Altimeter Missions: The Role of High-Frequency Signals. J. Atmos. Oceanic Technol., 19, 2077-2087.

○ Le Traon, P.Y., Faugère Y., Hernandez F., Dorandeu J., Mertz F. and M. Ablain, (2003). Can we merge GEOSAT Follow-On with TOPEX/POSEIDON and ERS-2 for an improved description of the ocean circulation? Journal of Atmospheric and Oceanic Technology, 20, 889-895.

L Le Traon, P.Y. and G. Dibarboure, (2004). Illustration of the contribution of the tandem mission to mesoscale studies. Marine Geodesy, 27, 3-13.

○ Le Traon P.Y., P. Klein, B.L. Hua and G. Dibarboure, (2008). Do altimeter data agree with interior or surface quasi-geostrophic theory. Journal of Physical Oceanography, Volume 38 (5), 1137-1142.

- May, D., and J. Hawkins (1991), Impact of the Geosat Altimeter Wet Tropospheric Range Correction in the Greenland-Iceland-Norwegian Sea, J. Geophys. Res., 96(C4), 72377247.

○ Pascual, A., Y. Faugère, G. Larnicol, P.-Y. Le Traon (2006). "Improved description of the ocean mesoscale variability by combining four satellites altimeters." Geophys Reseach Letters 33(doi:10.1029/2005GL024633).

○ Pascual A., C. Boone, G Larnicol, P.Y. Le Traon (2008) On the quality of real time altimeter gridded fields: comparison with in situ data, Journal of Atmospheric and Oceanic Technology, in press.

○ Pavlis.N, Holmes.S., Kenyon.S. and Factor.J. (2008), An Earth gravitational model to degree 2160: EGM 2008, Presented at EGU

○ General Assembly 2008, Vienna, Austria, April 13-18, 2008. http://earthinfo.nga.mil/GandG/wgs84/gravitymod/egm2008/index.html

○ Phalippou, L.; L.Rey; P. de Chateau-Thierry (2001): Overview of the performances and tracking design of the SIRAL altimeter for the CryoSat-2 mission. Geoscience and Remote Sensing Symposium, 2001. IGARSS '01. IEEE 2001 International, (doi: 10.1109/IGARSS.2001.978261)

- Philipps.S., M.Ablain, H.Roinard, E. Bronner, N.Picot (2012): Jason-2 global error budget for time scales lower than 10 days, Presented at the 2012 Ocean Surface Topography Science Team Meeting (Venise). Available online: http://www.aviso.oceanobs.com/fileadmin/documents/OSTST/2012/Philipps_jason2_global_error.pdf

- Raney.R.K (1998): The Delay/Doppler Radar Altimeter, IEEE Transactions on Geoscience and Remote Sensing, Vol. 36, No. 5., 1578 - 1588 (doi: 10.1109/36.718861) 
661

662

663

664

665

666

667

668

669

670

671

672

673

674

675

676

677

678

○ Sandwell, D. T., and W. H. F. Smith (2009), Global marine gravity from retracked Geosat and ERS-1 altimetry: Ridge segmentation versus spreading rate, J. Geophys. Res., 114, B01411, doi:10.1029/2008JB006008.

- Sandwell, D.T, E.Garcia, W.H.F.Smith (2011): Improved marine gravity from CryoSat and Jason-1. Presented at the 2011 ocean surface topography science team meeting. http://www.aviso.oceanobs.com/fileadmin/documents/OSTST/2011/ora//02_Thursday/Splinter\%202\%20GEO/06_\%20Sandwell.pdf

○ Schaeffer.P., Y. Faugère, JF. Legeais, A. Ollivier (2012): The CNES_CLS11 Global Mean Sea Surface computed from 16 years of satellite altimeter data. Marine Geodesy (In Press)

○ Stum, J., Sicard, P., Carrere, L., Lambin, J. (2011): Transations on Geoscience and Remote Sensing, Volume 49, Issue 9, Pages 3211 - 3224, doi: 10.1109/TGRS.2011.2104967.

- Tai, C.K. (1988), Geosat Crossover Analysis in the Tropical Pacific 1. Constrained Sinusoidal Crossover Adjustment, J. Geophys. Res., 93(C9), 10,621-10,629, doi:10.1029/JC093iC09p10621.

○ Thibaut, P., Poisson, J. C. , Bronner, E. and Picot, N.(2010) 'Relative Performance of the MLE3 and MLE4 Retracking Algorithms on Jason-2 Altimeter Waveforms', Marine Geodesy, 33: 1, 317 - 335

○ Wingham D.J., L. Phalippou, C. Mavrocordatos, and D. Wallis (2004): "The mean echo and echo cross-product from a beam-forming, interferometric altimeter and their application to elevation measurement," IEEE Trans. Geosci. Remote Sens., vol. 42, no. 10, pp. 2305-2323, Oct. 2004.

○ Wingham D.J., C.R. Francis, S. Baker, C. Bouzinac, D. Brockley, R. Cullen, P. de Chateau-Thierry, S.W. Laxon, U. Mallow, C. Mavrocordatos, L. Phalippou, G. Ratier, L. Rey, F. Rostan, P. Viau and D.W. Wallis (2006): CryoSat-2: A mission to determine the fluctuations in Earth's land and marine ice. Advances in Space Research, Volume 37, Issue 4, 2006, Pages 841-871

\section{Figure captions}

Figure 1: 10-day sampling from an altimeter on the TOPEX/Jason orbit. The white segment highlights the along-track direction with one measurement every $7 \mathrm{~km}$, and the black segment highlights the worst case configuration in the cross-track direction with one measurement every $315 \mathrm{~km} x \cos ($ latitude).

Figure 2: Difference between LRM (a) and SARin (b) measurements in the optimal interpolation for common profiles of cross-track slope (c) and SSH (d). The SARin measurement allows to observe the cross-track slope in addition to the SSH profile given by the LRM mode. 
683 Figure 3: Simulated Gaussian field (plain line), observation by a LRM altimeter in the along684 track direction (dots, $30 \mathrm{~km}$ resolution), and reconstruction at each time step with an optimal interpolation (dashed line) with formal error estimates (grey bars). The upper figure shows the SSH (in $\mathrm{cm}$ ), and the bottom panel the SSH slope (in $\mu \mathrm{rad}$ ).

Figure 4: Simulated Gaussian field (plain line), observation by a LRM altimeter in the crosstrack direction (dots, $300 \mathrm{~km}$ resolution), and reconstruction at each time step with an optimal interpolation (dashed line) with formal error estimates (grey bars). The upper figure shows the

$690 \mathrm{SSH}$ (in $\mathrm{cm}$ ), and the bottom panel the SSH slope (in $\mu \mathrm{rad}$ ).

691 Figure 5: Simulated Gaussian field (plain line), observation by two LRM altimeters in the 692 cross-track direction (dots, $150 \mathrm{~km}$ resolution), and reconstruction at each time step with an 693 optimal interpolation (dashed line) with formal error estimates (grey bars). The upper figure 694 shows the SSH (in $\mathrm{cm}$ ), and the bottom panel the SSH slope (in $\mu \mathrm{rad}$ ).

696 Figure 6: Simulated Gaussian field (plain line), observation by one SARin altimeter in the 697 cross-track direction (dots couples, $300 \mathrm{~km}$ resolution), and reconstruction at each time step 698 with an optimal interpolation (dashed line) with formal error estimates (grey bars). The upper 699 figure shows the SSH (in cm), and the bottom panel the SSH slope (in $\mu \mathrm{rad}$ ).

$700 \quad$ Figure 7: Simulated Gaussian field (plain line), observation by two SARin altimeters in the 701 cross-track direction (dots couples, $300 \mathrm{~km}$ resolution), and reconstruction at each time step 702 with an optimal interpolation (dashed line) with formal error estimates (grey bars). The upper

703 figure shows the SSH (in cm), and the bottom panel the SSH slope (in $\mu \mathrm{rad}$ ).

704 Figure 8: Cross-track reconstruction error (in \% of signal variance) for one SARin altimeter as 705 a function of the cross-track slope observation error (standard deviation in $\mu \mathrm{rad}$ ). The black 
dotted lines show the reconstruction error for one LRM altimeter and the black dashed line

707 the reconstruction error for two LRM altimeters. The grey dashed line highlights the curve's 708 point of inflection.

709 Figure 9: Cross-track reconstruction error (in \% of signal variance) for two SARin altimeters as a function of the cross-track slope observation error (in $\mu \mathrm{rad})$. The black dashed lines show

711 the reconstruction error for two LRM altimeters and the black line the reconstruction error for

712 four LRM altimeters. The grey dashed line highlights the curve's point of inflection.

713 Figure 10: Cross-track reconstruction error (in \% of signal variance) for one SARin altimeter

714 as a function of the cross-track slope observation error (in $\mu \mathrm{rad}$ ) and for 3 levels of SSH 715 variability.

716 Figure 11: CryoSat-2's sampling for 15 consecutive days. Satellite tracks (white lines) are 717 aggregated in $500 \mathrm{~km}$ wide bands thanks to the 3 and 30 day sub-cycles, and interleaved with $718500 \mathrm{~km}$ bands with few/no satellite tracks.

719 Figure 12: Simulated Gaussian field (plain line), observation in the cross-track direction 720 (dots) by one SARin altimeter on the CryoSat-2 orbit (100 km resolution, packet-aggregated 721 tracks), and reconstruction at each time step with an optimal interpolation (dashed line).

722 Difference between SARin observation (top) and LRM observation (bottom) to constrain 1D 723 OI reconstruction in the $500 \mathrm{~km}$ wide blind spot (grey rectangles).

724 Table 1: Reduction of the mapping error from LRM to SARin as a function of the simulation correlation radius. Unit: \% of the signal variance. Right-hand side columns show the

726 decreasing amplitude and slope of the eddy as a function of its radius (approximation of SQG 727 theory). 


\section{Figures}

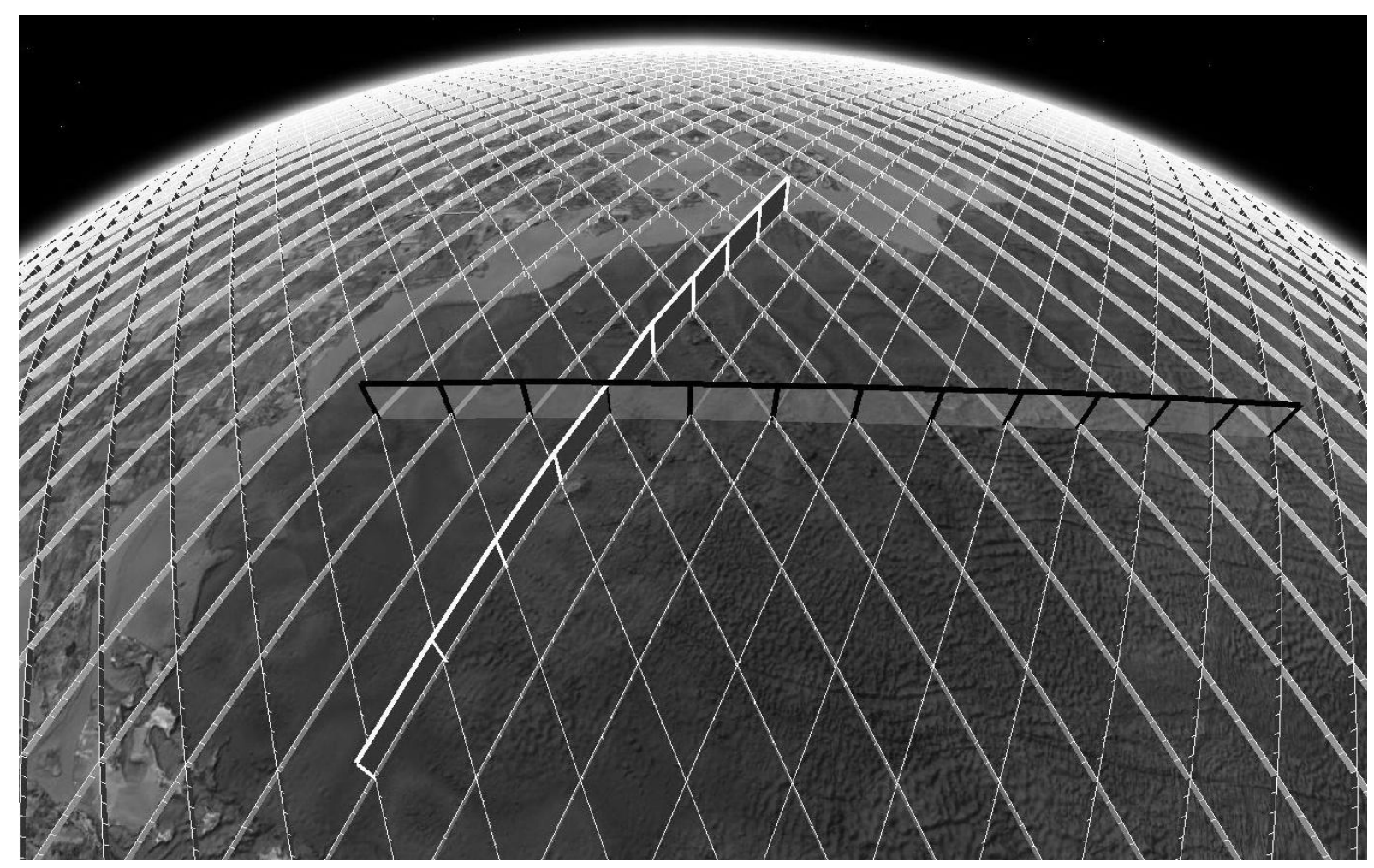

730 Figure 1 : 10-day sampling from an altimeter on the TOPEX/Jason orbit. The white segment 731 highlights the along-track direction with one measurement every $7 \mathbf{~ k m}$, and the black 732 segment highlights the worst case configuration in the cross-track direction with one 733 measurement every 315 km x cos(latitude). 
a) LRM sea surface height profile

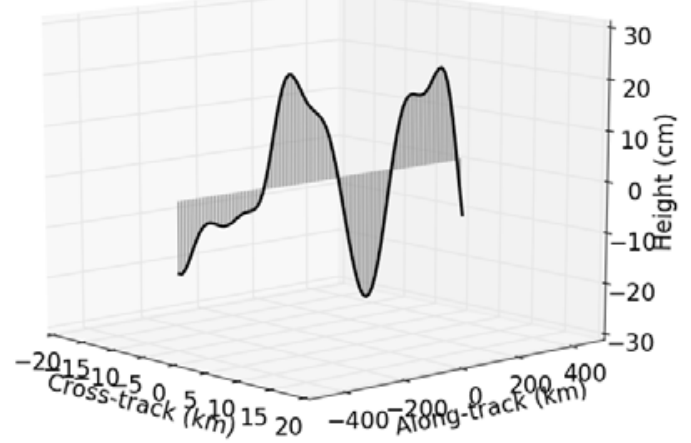

734

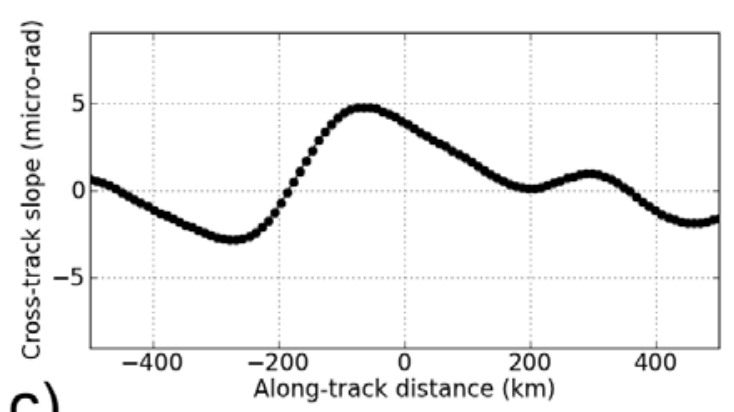

C)

b) SARin height \& slope profile
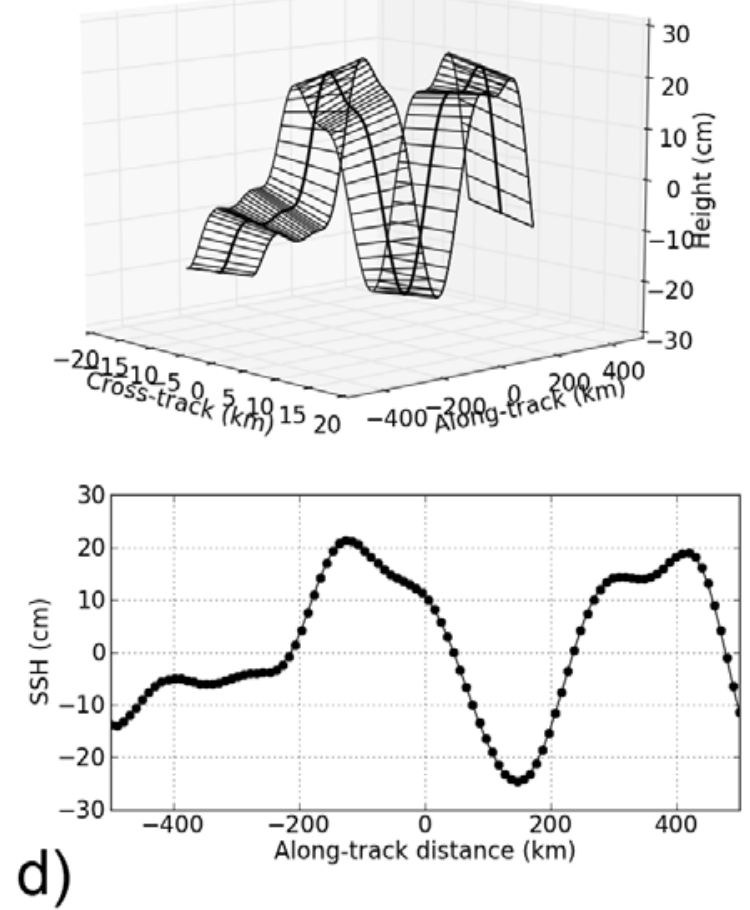

d)

735 Figure 2 : Difference between LRM (a) and SARin (b) measurements in the optimal interpolation for common profiles of cross-track slope (c) and SSH (d). The SARin measurement allows to observe the cross-track slope in addition to the SSH profile given by the LRM mode. 


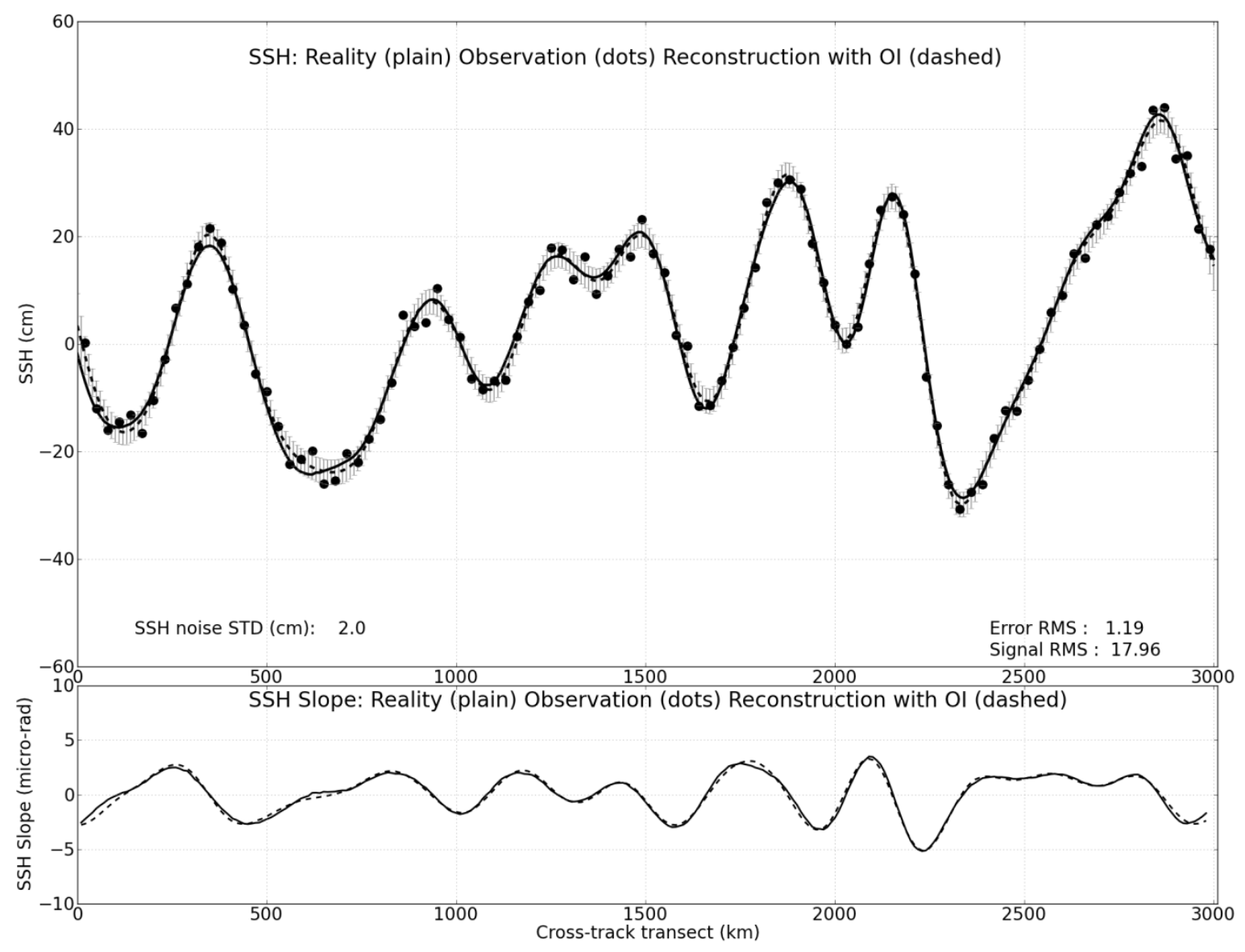

$741 \quad$ Figure 3 : Simulated Gaussian field (plain line), observation by a LRM altimeter in the along-track direction (dots, $30 \mathrm{~km}$ resolution), and reconstruction at each time step with an optimal interpolation (dashed line) with formal error estimates (grey bars). The upper figure shows the SSH (in $\mathrm{cm}$ ), and the bottom panel the SSH slope (in $\mu \mathrm{rad}$ ). 


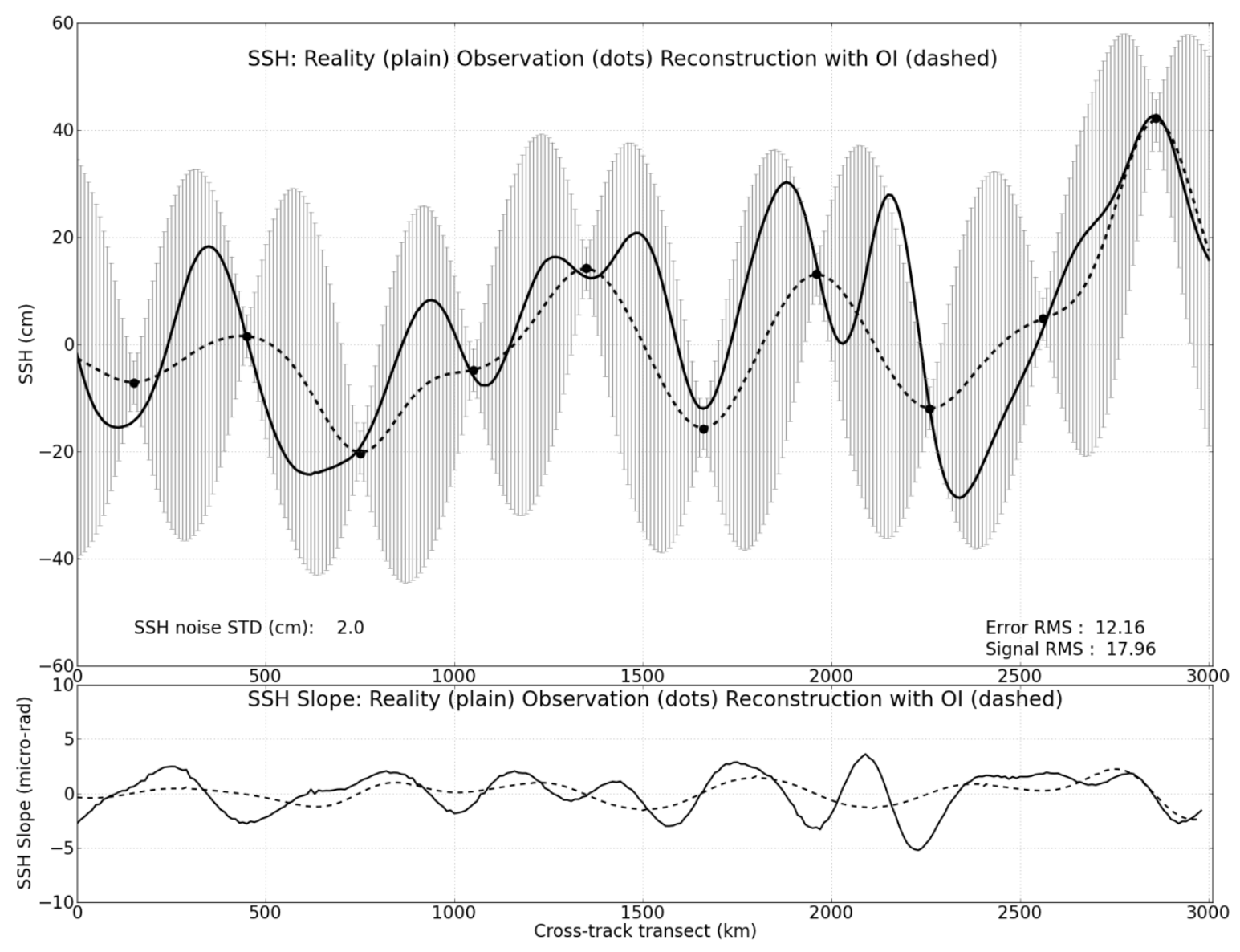

Figure 4 : Simulated Gaussian field (plain line), observation by a LRM altimeter in the crosstrack direction (dots, $300 \mathrm{~km}$ resolution), and reconstruction at each time step with an optimal interpolation (dashed line) with formal error estimates (grey bars). The upper figure shows the SSH (in $\mathrm{cm}$ ), and the bottom panel the SSH slope (in $\mu \mathrm{rad}$ ). 


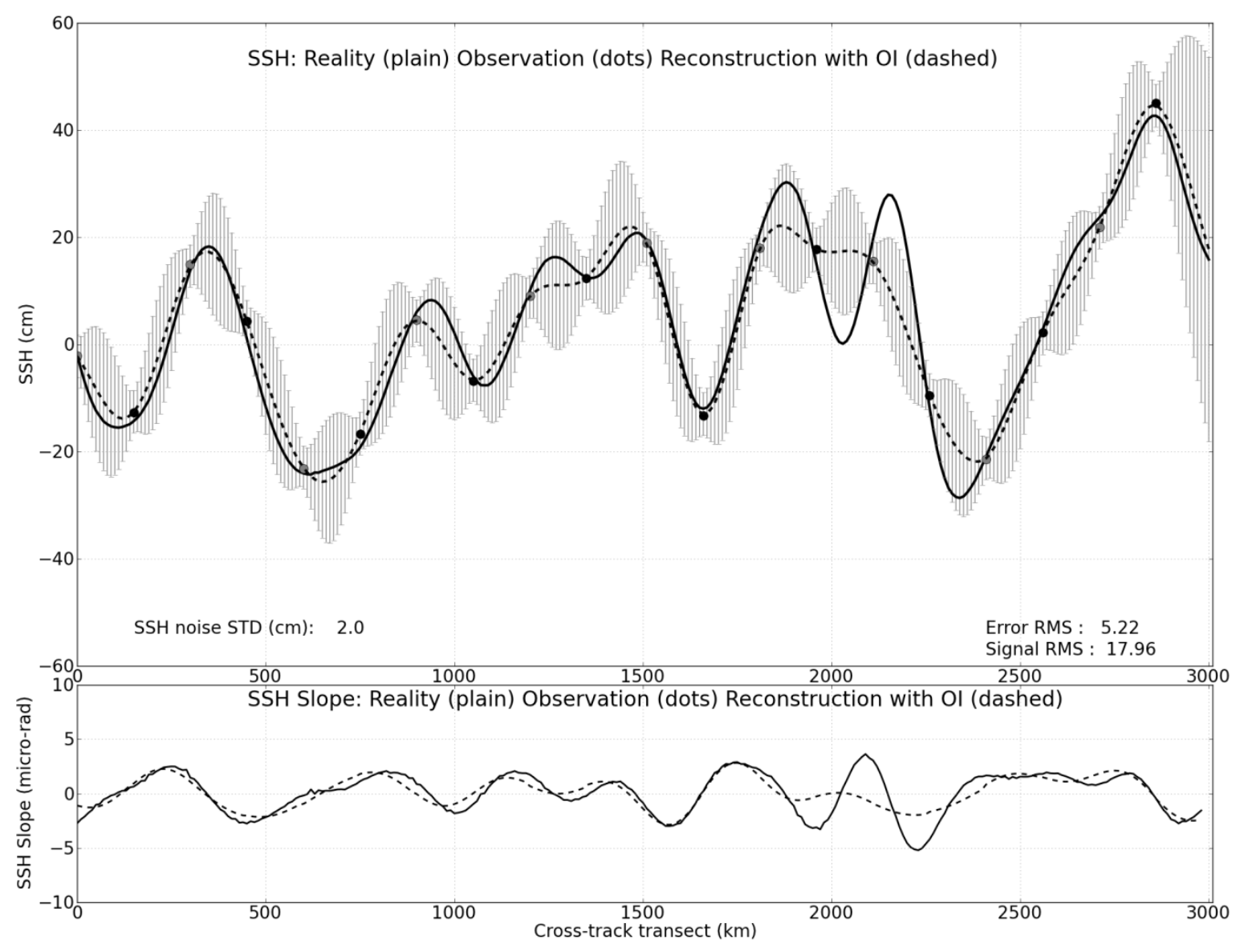

751 Figure 5 : Simulated Gaussian field (plain line), observation by two LRM altimeters in the cross-track direction (dots, $150 \mathrm{~km}$ resolution), and reconstruction at each time step with an optimal interpolation (dashed line) with formal error estimates (grey bars). The upper figure shows the SSH (in $\mathrm{cm}$ ), and the bottom panel the SSH slope (in $\mu \mathrm{rad}$ ). 


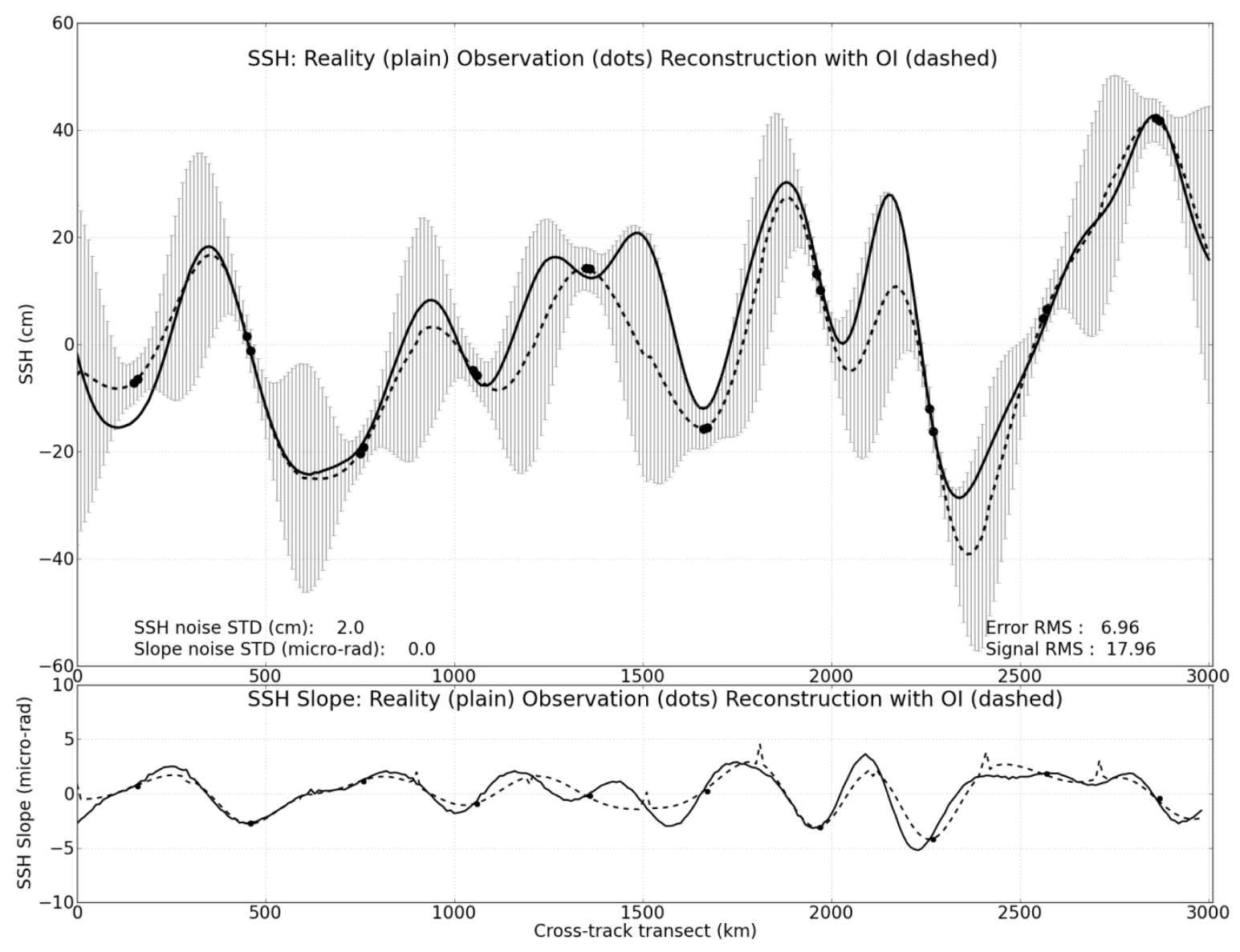

Figure 6 : Simulated Gaussian field (plain line), observation by one SARin altimeter in the cross-track direction (dots couples, $300 \mathrm{~km}$ resolution), and reconstruction at each time step with an optimal interpolation (dashed line) with formal error estimates (grey bars). The upper figure shows the SSH (in $\mathrm{cm}$ ), and the bottom panel the SSH slope (in $\mu \mathrm{rad}$ ). 


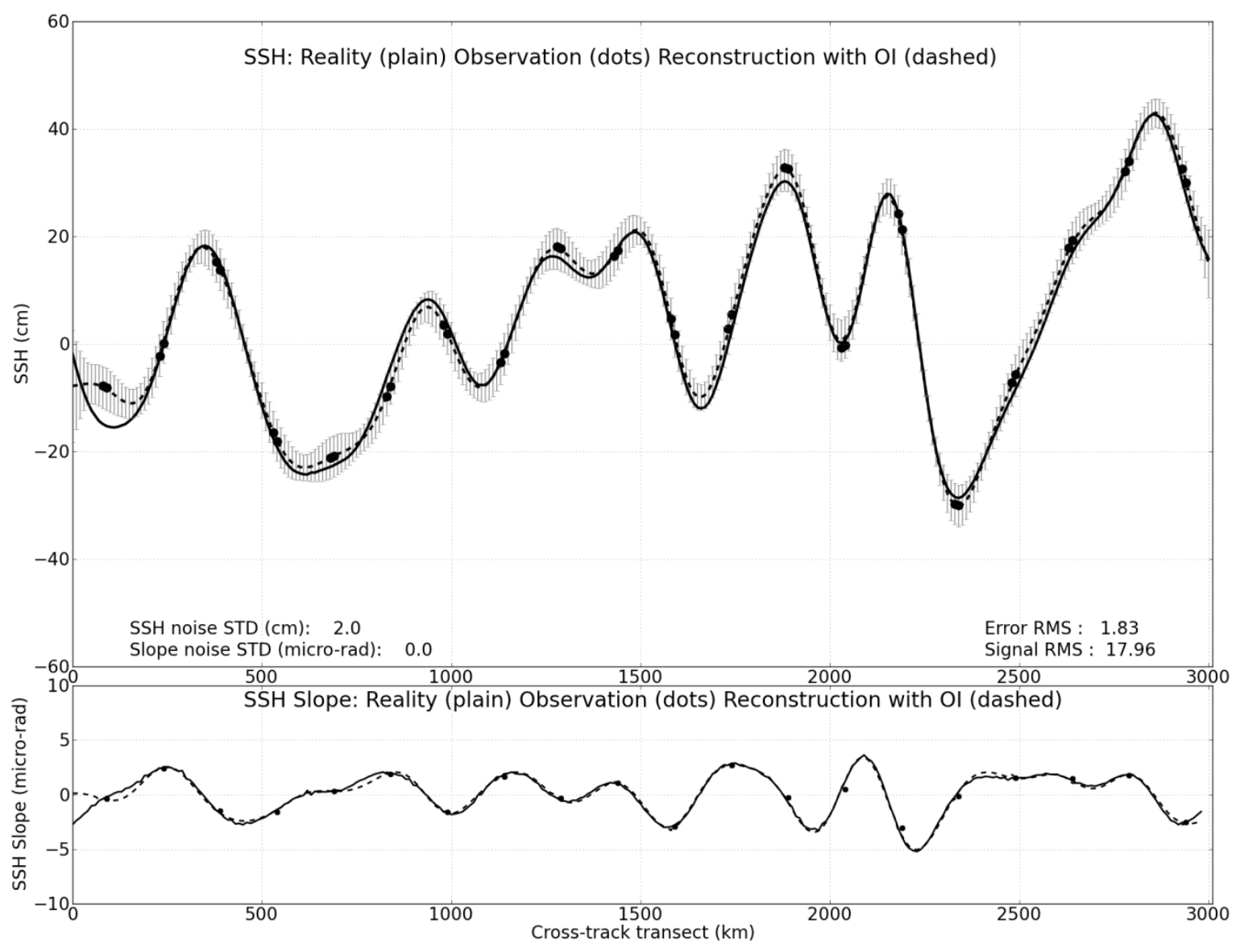

761 Figure 7 : Simulated Gaussian field (plain line), observation by two SARin altimeters in the cross-track direction (dots couples, $300 \mathrm{~km}$ resolution), and reconstruction at each time step with an optimal interpolation (dashed line) with formal error estimates (grey bars). The upper figure shows the SSH (in $\mathrm{cm}$ ), and the bottom panel the SSH slope (in $\mu \mathrm{rad}$ ). 


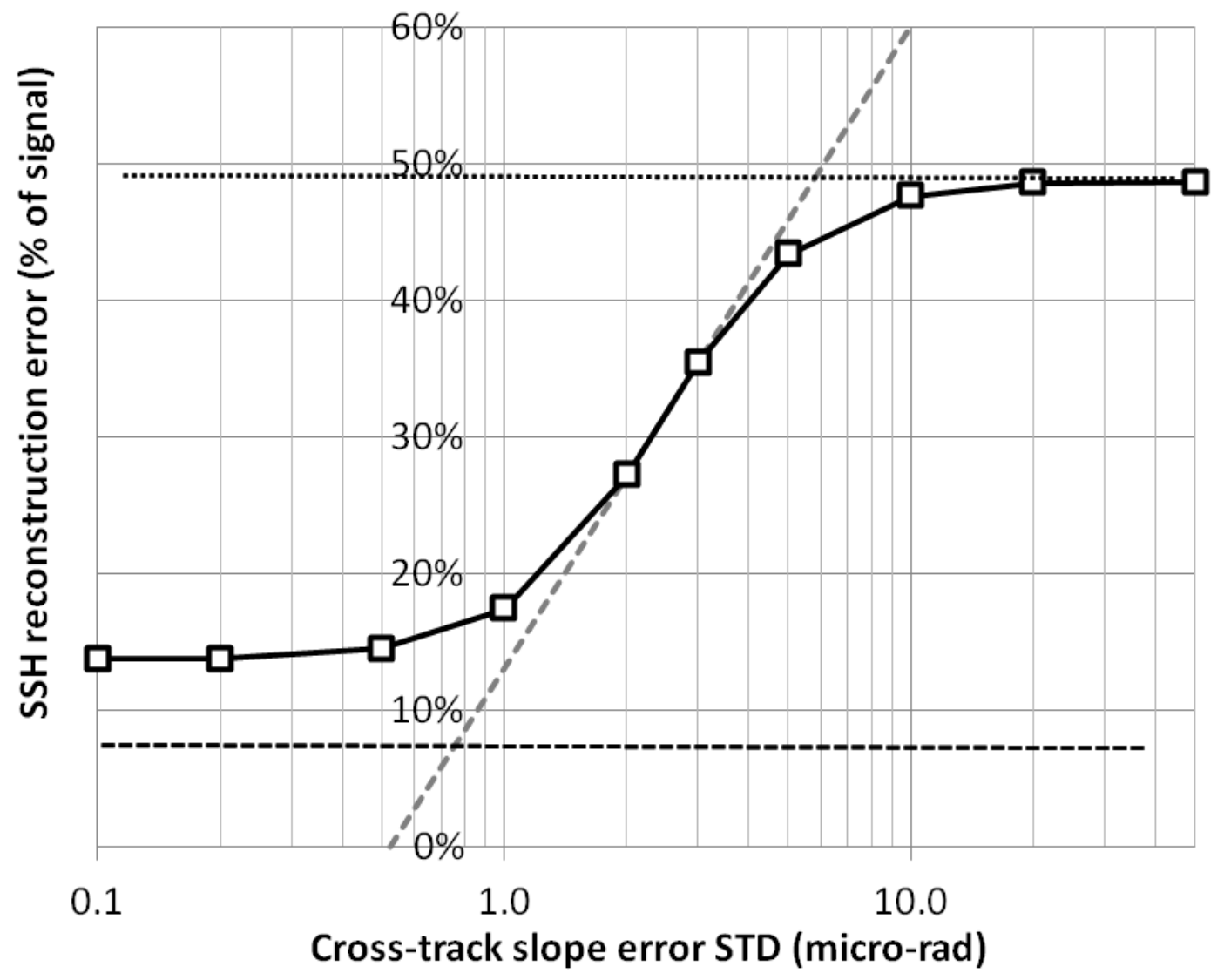

766 Figure 8 : Cross-track reconstruction error (in \% of signal variance) for one SARin altimeter as a function of the cross-track slope observation error (standard deviation in $\mu \mathrm{rad}$ ). The black dotted lines show the reconstruction error for one LRM altimeter and the black dashed line the reconstruction error for two LRM altimeters. The grey dashed line

770 highlights the curve's point of inflection. 


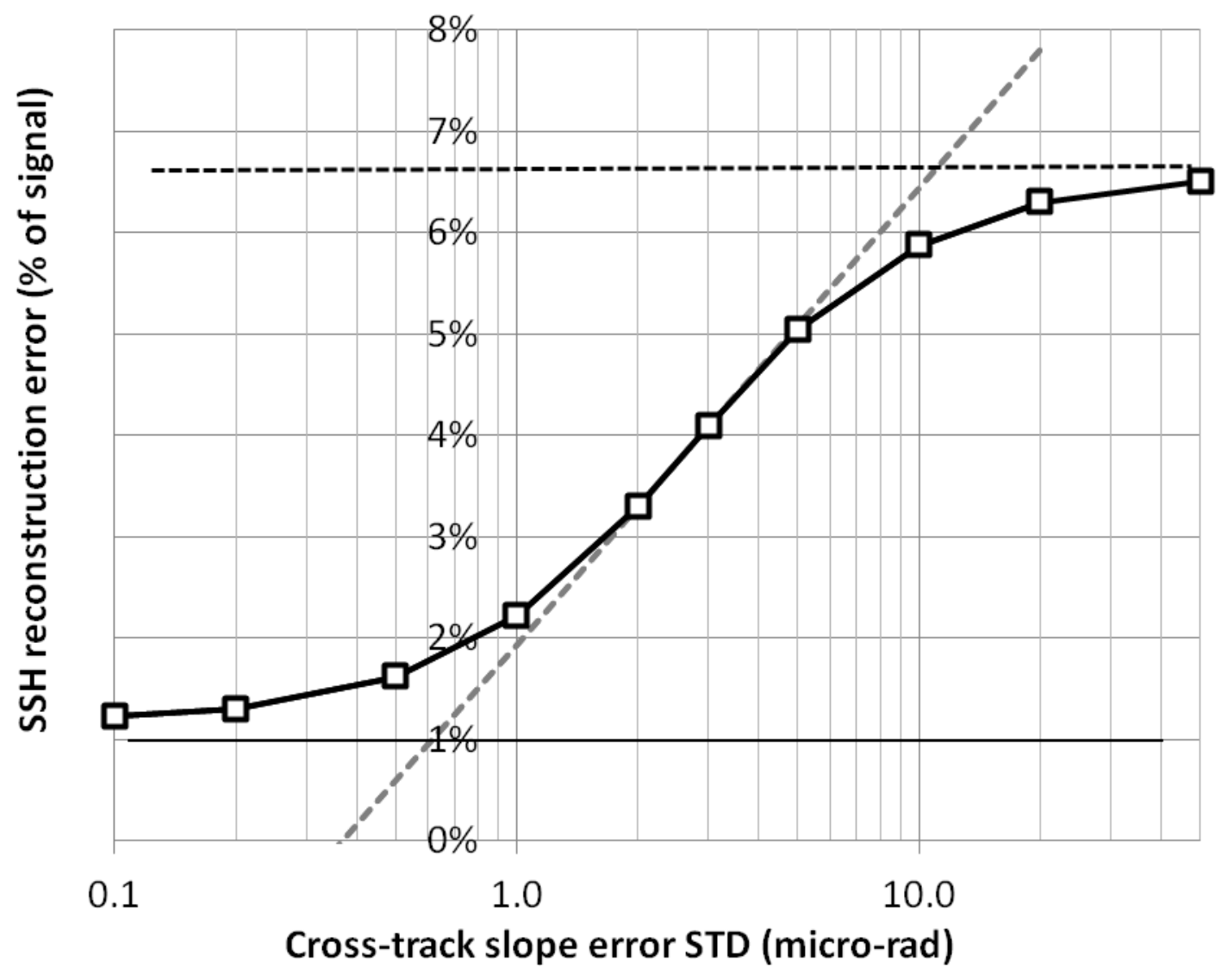

772 Figure 9 : Cross-track reconstruction error (in \% of signal variance) for two SARin altimeters as a function of the cross-track slope observation error (in $\mu \mathrm{rad}$ ). The black dashed lines

774 show the reconstruction error for two LRM altimeters and the black line the

775 reconstruction error for four LRM altimeters. The grey dashed line highlights the curve's

776 point of inflection. 


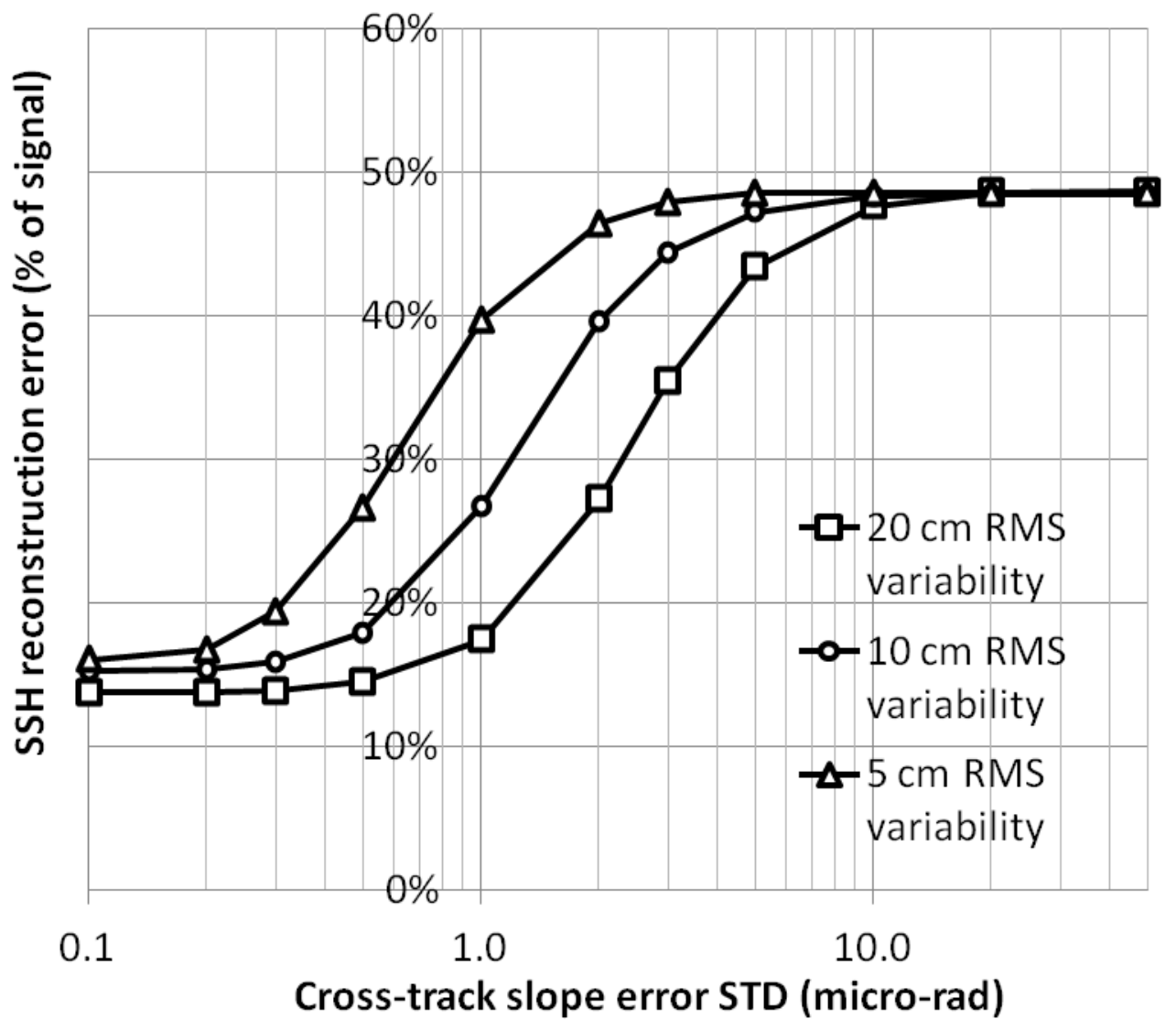

778 Figure 10 : Cross-track reconstruction error (in \% of signal variance) for one SARin

779 altimeter as a function of the cross-track slope observation error (in $\mu \mathrm{rad}$ ) and for $\mathbf{3}$ levels 780 of SSH variability. 


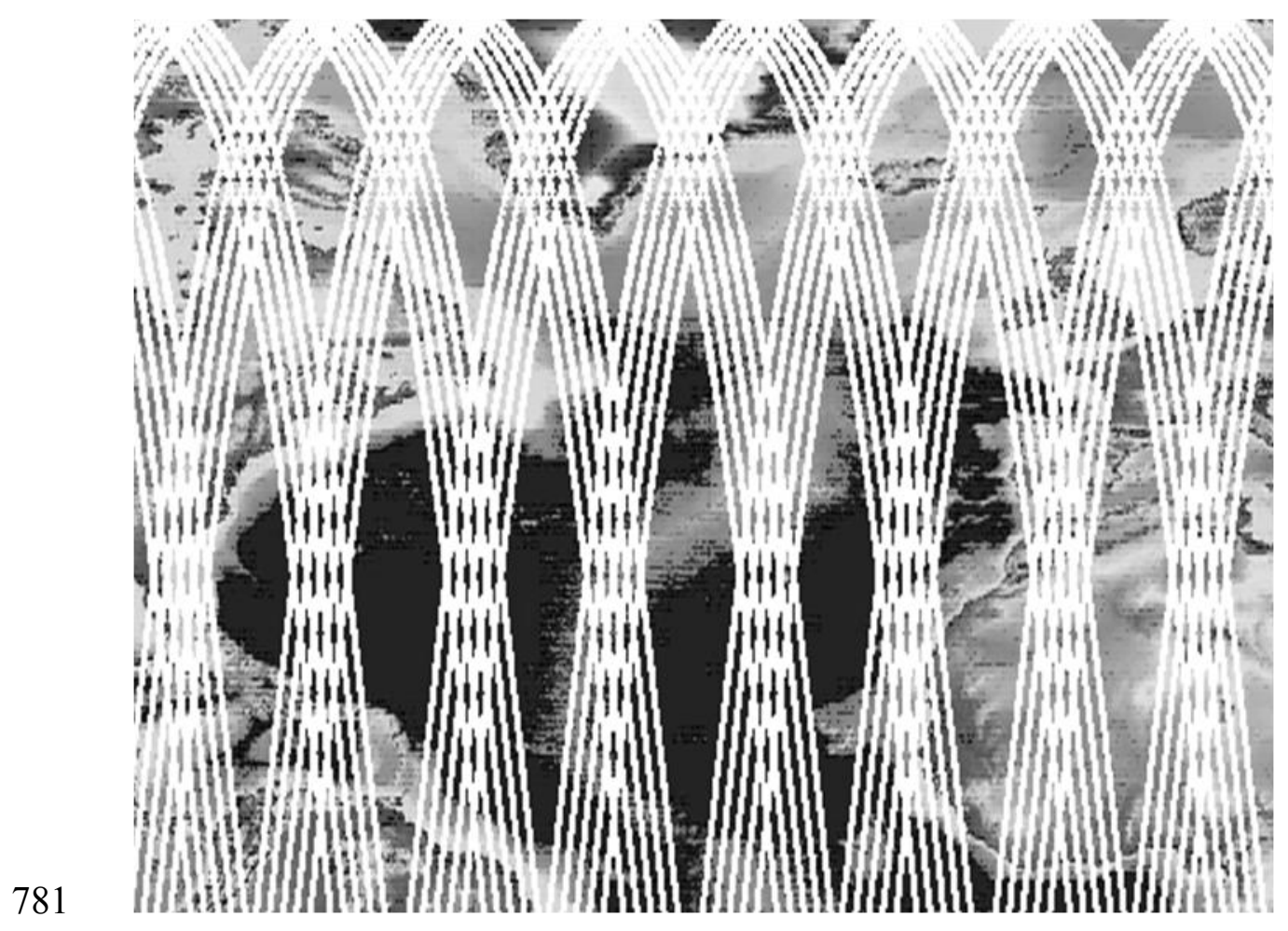

782 Figure 11 : CryoSat-2's sampling for 15 consecutive days. Satellite tracks (white lines) are 783 aggregated in $\mathbf{5 0 0} \mathbf{~ k m}$ wide bands thanks to the $\mathbf{3}$ and $\mathbf{3 0}$ day sub-cycles, and interleaved 784 with $\mathbf{5 0 0} \mathbf{~ k m}$ bands with few/no satellite tracks. 

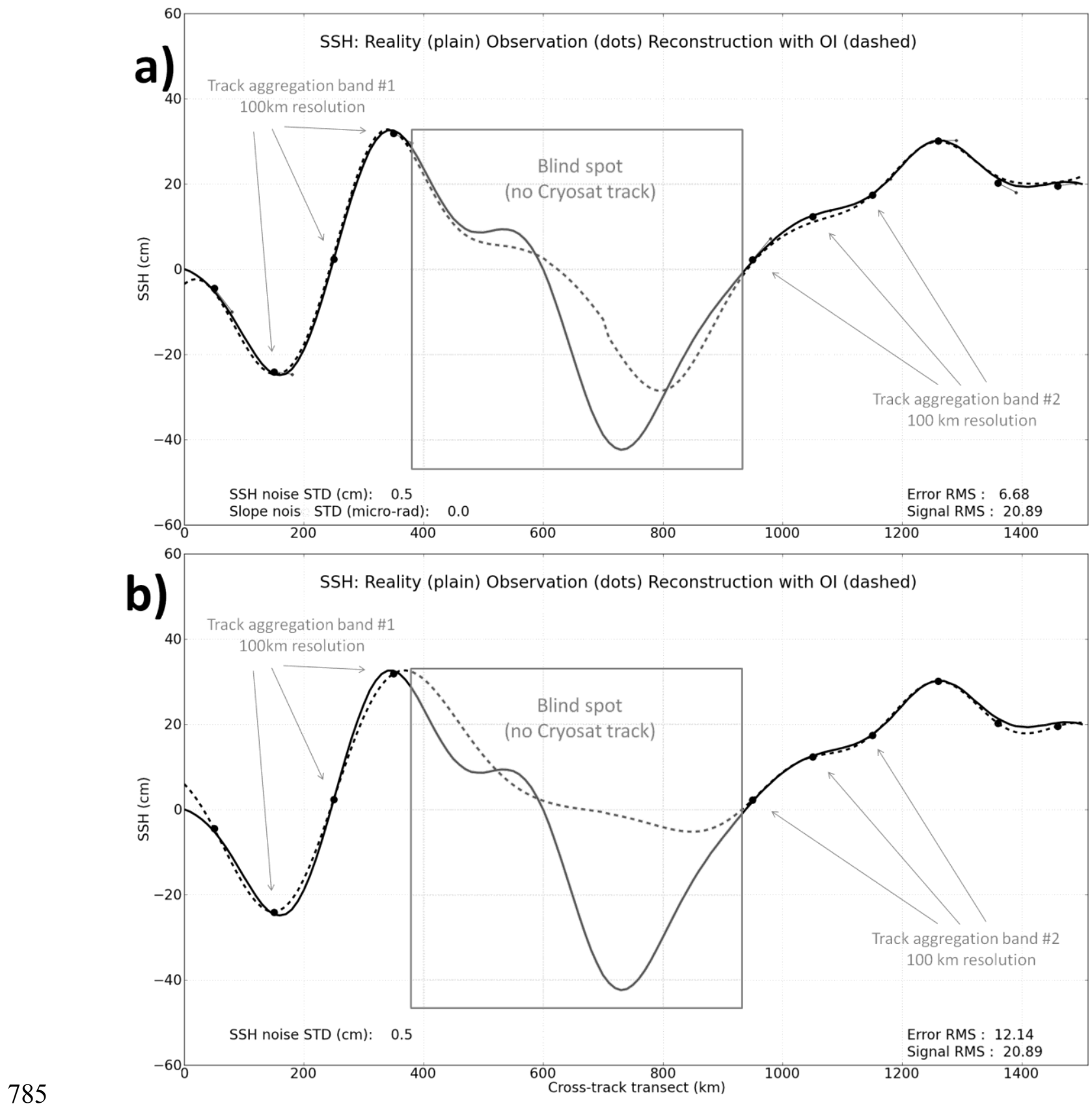

786 Figure 12 : Simulated Gaussian field (plain line), observation in the cross-track direction (dots) by one SARin altimeter on the CryoSat-2 orbit (100 km resolution, packetaggregated tracks), and reconstruction at each time step with an optimal interpolation (dashed line). Difference between SARin observation (top) and LRM observation (bottom) to constrain 1D Ol reconstruction in the $500 \mathrm{~km}$ wide blind spot (grey rectangles). 


\begin{tabular}{|r|r|r|r|r|}
\cline { 2 - 5 } \multicolumn{1}{c|}{} & \multicolumn{2}{|c|}{ Mapping Improvement } & \multicolumn{2}{c|}{ Reality signal properties } \\
\hline \multicolumn{1}{|c}{ Radius } & \multicolumn{1}{c|}{$\begin{array}{c}\text { Cryosat-2 } \\
\text { Orbit }\end{array}$} & $\begin{array}{c}\text { TP/Jason } \\
\text { Orbit }\end{array}$ & $\begin{array}{c}\text { SSH STD } \\
\text { (cm) }\end{array}$ & $\begin{array}{c}\text { SSH Slope } \\
\text { STD }(\boldsymbol{\mu r a d )}\end{array}$ \\
\hline 150 & $0 \%$ & $18 \%$ & 20.0 & 1.9 \\
\hline 125 & $1 \%$ & $9 \%$ & 15.8 & 1.8 \\
\hline 100 & $2 \%$ & $7 \%$ & 11.8 & 1.7 \\
\hline 75 & $8 \%$ & $5 \%$ & 8.1 & 1.5 \\
\hline 50 & $14 \%$ & $5 \%$ & 4.8 & 1.4 \\
\hline
\end{tabular}

792 Table 1: Reduction of the mapping error from LRM to SARin as a function of the simulation correlation radius. Unit: \% of the signal variance. Right-hand side columns show the decreasing amplitude and slope of the eddy as a function of its radius (approximation of

795 SQG theory). 